\title{
Gpr126/Adgrg6 Has Schwann Cell Autonomous and Nonautonomous Functions in Peripheral Nerve Injury and Repair
}

\author{
๑DAmit Mogha, ${ }^{1}$ @Breanne L. Harty, ${ }^{1}$ Dan Carlin, ${ }^{2}$ Jessica Joseph, ${ }^{1}$ Nicholas E. Sanchez, ${ }^{1}$ Ueli Suter, ${ }^{4}$ Xianhua Piao, ${ }^{5}$ \\ Valeria Cavalli, ${ }^{2,3}$ and Kelly R. Monk ${ }^{1,3}$ \\ ${ }^{1}$ Department of Developmental Biology, ${ }^{2}$ Department of Neuroscience, and ${ }^{3}$ Hope Center for Neurological Disorders, Washington University School of \\ Medicine, St. Louis, Missouri 63110, ${ }^{4}$ Institute of Molecular Health Sciences, Department of Biology, Swiss Federal Institute of Technology, Zurich, ETH \\ Zurich, CH-8093 Zurich, Switzerland, and 5Division of Newborn Medicine, Department of Medicine, Boston Children's Hospital and Harvard Medical \\ School, Boston, Massachusetts 02115
}

Schwann cells (SCs) are essential for proper peripheral nerve development and repair, although the mechanisms regulating these processes are incompletely understood. We previously showed that the adhesion G protein-coupled receptor Gpr126/Adgrg6 is essential for SC development and myelination. Interestingly, the expression of Gpr126 is maintained in adult SCs, suggestive of a function in the mature nerve. We therefore investigated the role of Gpr126 in nerve repair by studying an inducible SC-specific Gpr126 knock-out mouse model. Here, we show that remyelination is severely delayed after nerve-crush injury. Moreover, we also observe noncell-autonomous defects in macrophage recruitment and axon regeneration in injured nerves following loss of Gpr126 in SCs. This work demonstrates that Gpr126 has critical SC-autonomous and SC-nonautonomous functions in remyelination and peripheral nerve repair.

Key words: adhesion GPCR; Gpr126; nerve injury; remyelination; Schwann cell

\section{Significance Statement}

Lack of robust remyelination represents one of the major barriers to recovery of neurological functions in disease or following injury in many disorders of the nervous system. Here we show that the adhesion class G protein-coupled receptor (GPCR) Gpr126/Adgrg6 is required for remyelination, macrophage recruitment, and axon regeneration following nerve injury. At least $30 \%$ of all approved drugs target GPCRs; thus, Gpr126 represents an attractive potential target to stimulate repair in myelin disease or following nerve injury.

\section{Introduction}

In the peripheral nervous system (PNS), specialized glia known as Schwann cells (SCs) are best known for their role in generating

Received 0ct. 24, 2015; revised Sept. 25, 2016; accepted 0ct. 12, 2016.

Author contributions: A.M., B.L.H., D.C., and K.R.M. designed research; A.M., B.L.H., D.C., J.J., and N.E.S. performed research; U.S., X.P., and V.C. contributed unpublished reagents/analytic tools; A.M., B.L.H., D.C., J.J., N.E.S., and K.R.M. analyzed data; A.M., B.L.H., and K.R.M. wrote the paper.

This work was supported by National Institutes of Health (NIH) grant F31NS094004 to B.L.H., the Swiss National Science Foundation to U.S., NIH grants DE022000 and NS082446 to V.C., by a grant from the Muscular Dystrophy Association (MDA293295) to X.P. and K.R.M., and by NIH grant NS079445 to K.R.M. We thank Peter Arthur-Farraj for valuable conversations, Aaron DiAntonio for helpful suggestions as well as the SCG10 antibody, Albina Jablonka for assistance with extensor digitorum longus muscle dissection and for providing related reagents, and Monk and Cavalli laboratory members for critical feedback and discussions. We also thank Charleen Johnson and Zachary Spence for excellent mouse care and Robyn Roth and Marilyn Levy for transmission electron microscopy assistance. The authors declare no competing financial interests.

Correspondence should be addressed to Kelly R. Monk, Department of Developmental Biology, Washington University School of Medicine, 660 South Euclid Avenue, ML 8103, St. Louis, Missouri 63110. E-mail: monkk@wustl.edu

J. Joseph's present address: Johns Hopkins University, Baltimore, MD 21205 the myelin sheath during development, which enables rapid action potential propagation. Yet, following nerve injury, SCs are also vital players in repair. Axons distal to an injury site undergo Wallerian degeneration, a programmed cellular response that drives axon fragmentation. SCs associated with these degenerating axons also respond in a stereotyped fashion, becoming "Büngner" or repair SCs, which are essential mediators of nerve repair. Repair SCs downregulate the expression of genes associated with myelination and upregulate genes associated with immature SC stages. Further, repair SCs also upregulate neurotrophic factors and cytokines, which promote neuronal survival and macrophage recruitment, respectively (Arthur-Farraj et al., 2012). The macrophages recruited by SCs phagocytose axon and myelin debris, and SCs themselves also efficiently clear debris by a specialized form of autophagy (Gomez-Sanchez et al., 2015). Following nerve injury, axons regrow through Büngner bands- 
repair SC-containing basal lamina tubes-back to their targets. Once SC-axon contact is reestablished, repair SCs differentiate and remyelinate the regenerated axons, which is necessary to restore optimal nerve function following repair.

Although there are some differences between developmental myelination and remyelination following injury, many of the same molecular programs are reinitiated during repair. For example, the transcription factors Oct-6 (Pou3f1) and Krox-20 (Egr2) are similarly expressed in both contexts, with transient Oct-6 expression following axon contact that in turn regulates Krox-20 and subsequent myelin gene expression (Scherer et al., 1994; Zorick et al., 1996; Chen et al., 2007). During development, Oct-6, Krox-20, and myelin gene expression, as well as myelination, are all downstream of Gpr126 (Adgrg6) activation in SCs (Monk et al., 2009, 2011; Mogha et al., 2013). Gpr126 is a member of the adhesion $G$ protein-coupled receptor (aGPCR) class; aGPCRs possess, in addition to a seven-transmembrane domain that couples to heterotrimeric G-proteins, a long N-terminal region rich in functional motifs often involved in cell-cell or cellmatrix adhesion. Most aGPCRs undergo an autocleavage event that splits the receptor into two fragments, and recent studies demonstrate that this autocleavage can generate a tethered agonist ligand in many aGPCRs (Liebscher et al., 2014; Demberg et al., 2015; Stoveken et al., 2015). In the case of Gpr126, activation by the tethered agonist is required for SC myelination (Liebscher et al., 2014; Petersen et al., 2015), and we recently determined that laminin-211 binds the N-terminus of Gpr126 and modulates the availability of the tethered agonist (Petersen et al., 2015).

Despite the essential function of Gpr126 in SC development, it is unknown whether this aGPCR is similarly required for remyelination following injury. Moreover, Gpr126 is robustly expressed in mature SCs (Mogha et al., 2013), but its function in adult nerve is not fully understood. In the present study, we use tamoxifen-inducible conditional mouse models to investigate the role of Gpr126 in SCs following nerve injury. We show that while Gpr126 is dispensable for myelin maintenance up to 4 months, this aGPCR has key SC-autonomous and SCnonautonomous functions during injury and repair. Mirroring its role in development, we show that Gpr126 is required in SCs for remyelination. Unexpectedly, we also find that Gpr126 is required in SCs for increased macrophage numbers in the distal stump as well as efficient axon regeneration following injury. Importantly, mutations in LAMA2, which encodes the $\alpha 2$ chain of the Gpr126-binding partner laminin-211, cause merosindeficient congenital muscular dystrophy (MDC1A) in humans, and $80 \%$ of these patients present with a dysmyelinating neuropathy (Shorer et al., 1995; Mercuri et al., 1996; Quijano-Roy et al., 2004). Therefore, this work has important implications for repair in MDC1A patients and potentially for other peripheral nerve diseases as well.

\section{Materials and Methods}

Mice. All animal experiments were performed in compliance with Washington University's institutional animal protocols. Gpr $126^{f l / f l}$ mice, PLP ${ }^{\text {Cre-ERT2 }}$ mice, Dhh ${ }^{\text {Cre }}$ mice, RosaLacZ mice, and genotyping assays have been previously described (Soriano, 1999; Jaegle et al., 2003; Leone et al., 2003; Mogha et al., 2013). For all experiments, mice of both sexes were analyzed and we always compared littermate sibling controls.

Tamoxifen injections. For all experiments involving "icKO mice," $P L P^{\text {Cre-ERT2 }}$; Gpr $126^{f l f l} ; \mathrm{Rosa}^{+}$animals were injected daily with either tamoxifen (in 9:1 sunflower oil/ethanol) to induce the Cre recombinase activity or with solvent only (control; 9:1 sunflower oil/ethanol). We injected animals beginning at 8 weeks of age once per day at $2 \mathrm{mg} / \mathrm{ml}$ for 5 consecutive days. For myelin maintenance experiments, we analyzed
$N=3$ control-injected and tamoxifen-injected animals 4 weeks following the final injections and $N=3$ control-injected and tamoxifeninjected animals 4 months following the final injections.

Nerve crush. Sciatic nerves of right hind limbs were crushed 4 weeks following the final control or tamoxifen injection according to standard protocols (Akassoglou et al., 2002; Bauder and Ferguson, 2012). Briefly, mice were anesthetized by isofluorane before and during surgery. Fur was removed with an electric trimmer and the sciatic nerve of the right hindlimb was exposed by making a small cut in the skin. The exposed sciatic nerve was carefully crushed with number 5 forceps as described previously (Bauder and Ferguson, 2012), and the crush site was marked with powdered carbon. After crush, surgical wounds were sutured with nylon thread and sealed with metal clips. Mice were administered painreducing chow (Bio Serv) during recovery until they were killed. We used a minimum of $N=3$ mice for control-injected and tamoxifen-injected groups at each time point.

Nerve and muscle harvest. Following the nerve injury, sciatic nerves were harvested at $3,7,21$, or $35 \mathrm{~d}$ postinjury (dpi). For myelinmaintenance experiments, sciatic nerves were harvested at 4 weeks or 4 months after the last tamoxifen injection. We isolated a 1-cm-long segment from each sciatic nerve distal to the crush site, which was marked with powdered carbon. This 1-cm-long segment was cut in half; the more proximal $0.5 \mathrm{~cm}$ segment was always used for transmission electron microscopy (TEM), while the more distal $0.5 \mathrm{~cm}$ segment was always used for immunohistochemistry (IHC). These two halves of the nerve segment were drop-fixed in appropriate fixatives. The tissues were embedded such that the midpoint of the original $1 \mathrm{~cm}$ segment faced the front of the block face for sectioning so that TEM and IHC images derive from approximately the same distance $(0.5 \mathrm{~cm})$ from the crush site. For neuromuscular junction (NMJ) innervation experiments, extensor digitorum longus (EDL) muscles were isolated at $12 \mathrm{dpi}$ from the legs of mice whose sciatic nerves had been crushed as described above. EDL muscles from the uncrushed contralateral sides were used as controls.

IHC staining. Sciatic nerves were isolated as described above, dropfixed in $4 \%$ paraformaldehyde (PFA) overnight at $4^{\circ} \mathrm{C}$, and processed as described previously (Mogha et al., 2013) for all stains except for Gpr126 and SCG10. For Gpr126 staining, nerves were drop-fixed in 4\% PFA for $30 \mathrm{~min}$ at room temperature and then processed as described previously (Giera et al., 2015). For EDL muscle, tissue was drop-fixed overnight at $4^{\circ} \mathrm{C}$ after sticking on a piece of a toothpick to avoid curling. After washing with PBS, muscle was kept in 30\% sucrose solution and then cryosectioned longitudinally at $20 \mu \mathrm{m}$ thickness. The following primary antibodies were used: rabbit anti-Gpr126 ${ }^{\mathrm{CTF}}$ (1:10; Petersen et al., 2015), rat anti-MBP (1:10; Bio-Rad Laboratories), chicken anti-lacZ (1:400; Abcam), rabbit anti-c-Jun (1:400; Cell Signaling Technology), rabbit antis100 (1:400; Dako Cytomation), rat anti-CD68 (1:50; Abcam), rabbit anti-Ki67 (1:400; Abcam), rabbit anti-SCG10 (1:2000; Shin et al., 2014), goat anti-Iba1 (1:200; Abcam), and rabbit anti-NF-200 (1:500; SigmaAldrich). For NMJ stains, $\alpha$-bungarotoxin (BTX)-Alexa Fluor 555 (Invitrogen) was used. After three washes in PBS, sections were incubated with the appropriate fluorescently labeled secondary antibodies (1:1000; Invitrogen) suspended in blocking buffer for $1 \mathrm{~h}$ at room temperature. After further washing in PBS, slides were mounted using Vectashield with DAPI (Vector Labs) to label nuclei. Fluorescent images were obtained with a Zeiss AxioImager M2 microscope.

Western blotting. Sciatic nerves were isolated from mice at $3 \mathrm{dpi}$. Segments of uninjured and distal injured sciatic nerve measuring $1 \mathrm{~cm}$ in length were homogenized in lysis buffer (Cell Signaling Technology) with protease and phosphatase inhibitors (Roche). Fifteen micrograms of protein were loaded and analyzed by SDS-PAGE and western blot with the following antibodies: rabbit anti-c-Jun (1:1000; Cell Signaling Technology), rabbit anti- $\alpha$ tubulin (1:20,000; Abcam), and goat anti-rabbit IgG HRP (1:10,000; Life Technologies). Membranes were developed with SuperSignal West Pico (Thermo Fisher Scientific), imaged on a ChemiDoc MP imaging system (Bio-Rad Laboratories), and quantified with Image Lab 5.2.1 software (Bio-Rad Laboratories).

TEM. Sciatic nerves were isolated as described above, drop-fixed in modified Karnovsky's fixative (4\% PFA and 2\% glutaraldehyde in $0.1 \mathrm{M}$ sodium cacodylate, $\mathrm{pH} 7.4)$ at $4^{\circ} \mathrm{C}$ overnight, and processed as described 
previously (Monk et al., 2011). Semithin sections (200-300 nm) were stained with toluidine blue and viewed on a light microscope (Zeiss AxioImager M2). Images were recorded with an AxioCam MRm. Thin sections (70 $\mathrm{nm}$ ) were stained with uranyl acetate and Sato's lead stain and then viewed on a Jeol (JEM-1400) electron microscope. Images were recorded with an Advanced Microscopy Techniques V601 digital camera.

Bluo-gal staining. Mouse sciatic nerves were harvested as described above and were postfixed in 2\% PFA and $0.1 \%$ glutaraldehyde in $0.1 \mathrm{M}$ sodium cacodylate for $1 \mathrm{~h}$ at $4^{\circ} \mathrm{C}$. Nerves were processed with the bluogal solution as described previously (Aoyama et al., 2004). Briefly, nerve segments were incubated in bluo-gal solution ( $5 \mathrm{~mm}$ potassium ferricyanide plus $5 \mathrm{~mm}$ potassium ferrocyanide plus $2 \mathrm{mM} \mathrm{MgCl}_{2}$ plus $0.1 \%$ 5-bromo-3 indoyl- $\beta$-D-galactoside) at $37^{\circ} \mathrm{C}$ for $20 \mathrm{~h}$. Following this, nerves were postfixed in 2\% PFA and $2 \%$ glutaraldehyde in 0.1 m sodium cacodylate overnight at $4^{\circ} \mathrm{C}$. After this step, nerves were processed for TEM as described previously (Monk et al., 2011)

Morphometric quantifications. To calculate g-ratios, we manually measured axon diameter and axon-plus-myelin diameter in ImageJ. We measured 100 axons from $\sim 2200 \mu \mathrm{m}^{2}$ regions of nerve selected at random from $N=3$ for control-injected or tamoxifen-injected animals at each time point. The measurements were taken with the observer blind to treatment.

To calculate axon regrowth index, longitudinal sciatic nerve sections were made ( $7 \mu \mathrm{m}$ thick) at $3 \mathrm{dpi}$. These nerve sections were stained with anti-SCG10 as described previously (Shin et al., 2012). We measured distance of the longest SCG10 + axons from the crush site, measuring $\geq 5$ axons within a $0.2 \mathrm{~mm}$ distance. The lengths were normalized to the lengths of the corresponding sibling controls. We also counted the number of SCG10+ regenerated axons at standard distances from the crush site. Axons were counted at $0.5 \mathrm{~mm}$ intervals starting at $1.5 \mathrm{~mm}$ from the crush site. The number of axons at each given distance was normalized to $1 \mathrm{~mm}$. Averages were taken at each spot and were compared between control and tamoxifen groups for corresponding sites from the crush sites. At least three animals per group were examined, and measurements were taken with the observer blind to treatment or genotype.

To quantify myelin debris, we used ImageJ to define contours around myelin debris in $\sim 2200 \mu \mathrm{m}^{2}$ regions of TEM micrographs, and contour area was normalized to the total area. At least 10 randomly selected areas were quantified from $N=3$ animals per group, and measurements were taken with the observer blind to treatment. For axon numbers, we similarly quantified the total axon number from $\sim 2200 \mu \mathrm{m}^{2}$ regions of TEM micrographs. At least 10 randomly selected areas were quantified from $N=3$ animals per group, and measurements were taken with the observer blind to treatment.

To quantify molecular markers of SCs, proliferation, and macrophages, we manually counted the number of Ki67+ or c-Jun + nuclei, which were also positive for DAPI. The number of these nuclei was normalized to the total number of nuclei in the field of view. Macrophages were counted as CD68+ or IBA1 + cells and the numbers were normalized to the corresponding sibling control for each experiment. For LacZ + cells, we counted the LacZ + cells manually and normalized to the total number of SCs positive for S100. We used three animals for each group in each experiment, and quantifications were performed with the observer blind to treatment.

RNA extraction and reverse transcription. Total RNA was extracted from single sciatic nerves that had been flash frozen in liquid nitrogen using traditional three-phase separation with TRIzol (Life Technologies). Briefly, TRIzol was added to the frozen tissue samples, which were then homogenized using the following steps: the nerves were first cut into smaller pieces with dissection scissors, then disrupted with a plastictipped electric homogenizer, and finally passaged through a syringe and successively smaller needles (22.5 and $27 \mathrm{~g}) 10$ times each.

Total RNA (200 ng) was then reverse-transcribed in $20 \mu \mathrm{l}$ using Superscript III First Strand Synthesis with random hexamers (Invitrogen). The reaction mixture was incubated for $5 \mathrm{~min}$ at $65^{\circ} \mathrm{C}, 50 \mathrm{~min}$ at $50^{\circ} \mathrm{C}$, and for $5 \mathrm{~min}$ at $85^{\circ} \mathrm{C}$, as per the instructions from the manufacturer. To control for genomic DNA contamination, a noreverse transcriptase reaction $(\mathrm{RT}-$ ) was also performed for each RNA sample.
Quantitative reverse-transcription PCR. All assays were performed on a ViiA7 (Applied Biosystems) qPCR machine with $2 \times$ SsoFast Evagreen Supermix (Applied Biosystems). Cycling parameters were $95^{\circ} \mathrm{C}(10 \mathrm{~min})$ followed by 40 cycles of $95^{\circ} \mathrm{C}(15 \mathrm{~s})$, then $60^{\circ} \mathrm{C}(1 \mathrm{~min})$ with a ramp speed of $1^{\circ} \mathrm{C} / \mathrm{s}$. Melting curve analysis was completed as follows: $95^{\circ} \mathrm{C}(15 \mathrm{~s})$, $60^{\circ} \mathrm{C}(1 \mathrm{~min})$, and a progressive increase up to $95^{\circ} \mathrm{C}\left(0.5^{\circ} \mathrm{C} / \mathrm{min}\right)$.

Myelin gene expression was assayed using the following previously published primers: Sox10: 5'-CAGGTGTGGCTCTGCCCACG-3' and 5'GTGTAGAGGGGCCGCTGGGA-3'; $M b p: 5^{\prime}$-CCAAGTTCACCCCT ACTCCA-3' and 5'-TAAGTCCCCGTTTCCTGTTG-3' (Sox10 and Mbp; Finzsch et al., 2010); Oct6: 5'-TCGAGGTGGGTGTCAAAGG-3' and 5'GGCGCATAAACGTCGTCCA-3' (Zhu et al., 2014). Chemokine expression of 84 genes was evaluated using the 96-well format of the RT ${ }^{2}$ Profiler PCR Array: Chemokines and Receptors (mouse; Qiagen) for the ViiA7 machine. All qPCR data were analyzed using Microsoft Excel. Relative expression was calculated using the $\Delta \Delta$ Ct method (Livak and Schmittgen, 2001). All samples were normalized to the average expression of several stably expressed housekeeping control genes: ActB, B2m, GapDH, GusB, and Hsp90. Relative expression (RQ), or fold change $\left(2^{-\Delta \Delta \mathrm{Ct}}\right)$, is shown in figures. Error bars depict RQmax and RQmin, which are the maximum and minimum limits of possible RQ values based on the SD of the $\Delta \mathrm{Ct}$ values. Three biological replicates for all genotypes and sibling controls were performed.

Statistical analyses. All data are presented as the mean $+\mathrm{SD}$ or $\pm \mathrm{SD}$. Significance is represented as ${ }^{*} p<0.05$; $^{* *} p<0.01$; ${ }^{* * *} p<0.001$. Sample sizes are similar to those of previously published works. A minimum of three animals per genotype were used unless otherwise noted. Statistical analyses were performed using an unpaired Student's $t$ test with two tails or using ANOVA as indicated and in accordance with previously published works. Unequal variance and datasets analyzed by a Student's $t$ test met the appropriate assumptions, including normality.

\section{Results}

\section{Inducible deletion of Gpr126 from mature SCs}

Gpr126 is essential for SC development (Monk et al., 2009, 2011; Mogha et al., 2013; Petersen et al., 2015), yet we previously noted that Gpr126 is also highly expressed in mature SCs (Mogha et al., 2013), indicating additional possible roles of this aGPCR in adult nerve. To investigate the role of Gpr126 in the mature PNS, we generated SC-specific, tamoxifen-inducible conditional knockout mice by crossing previously described Gpr $126^{f l / f l}$ mice (Mogha et al., 2013) with mice expressing tamoxifen-inducible Cre recombinase under control of the PLP promoter (Leone et al., 2003). We also used the Rosa-LacZ locus as a reporter for Cre activity. Gpr126 ${ }^{f l f l} ; P L P^{C r e-E R T 2} ; R_{0 s a^{+}}$mice, hereafter referred to as icKO mice, were injected once per day with $2 \mathrm{mg}$ of tamoxifen or vehicle control (nine parts sunflower oil plus one part ethanol) at 8 weeks of age for 5 consecutive days. IHC analyses of sciatic nerve cross sections 4 weeks after injection using anti-Gpr 126 and LacZ antibodies revealed that the majority of SCs in tamoxifen-injected animals are Gpr126(-) and LacZ(+) (Fig. $1 B ; N=3$ animals). Some SCs are Gpr126(+) following tamoxifen administration, but all Gpr126(+) SCs are LacZ(-) (Fig. $1 B)$, indicating that Cre was not activated in these cells.

\section{Gpr126 deletion does not affect myelin maintenance up to 4 months.}

Having established that tamoxifen administration effectively deletes Gpr126 from mature SCs, we next sought to use this model to determine whether Gpr126 is required for remyelination after injury. Given that we have recently determined that loss of Gpr126 in SCs leads to axon-glial interaction defects after $\sim 1$ year of age (Küffer et al., 2016), we wanted to test whether Gpr126 is required for myelin maintenance in the short term (e.g., at time points to be examined in nerve-injury studies). To this end, we examined sciatic nerves of tamoxifen-injected and control- 

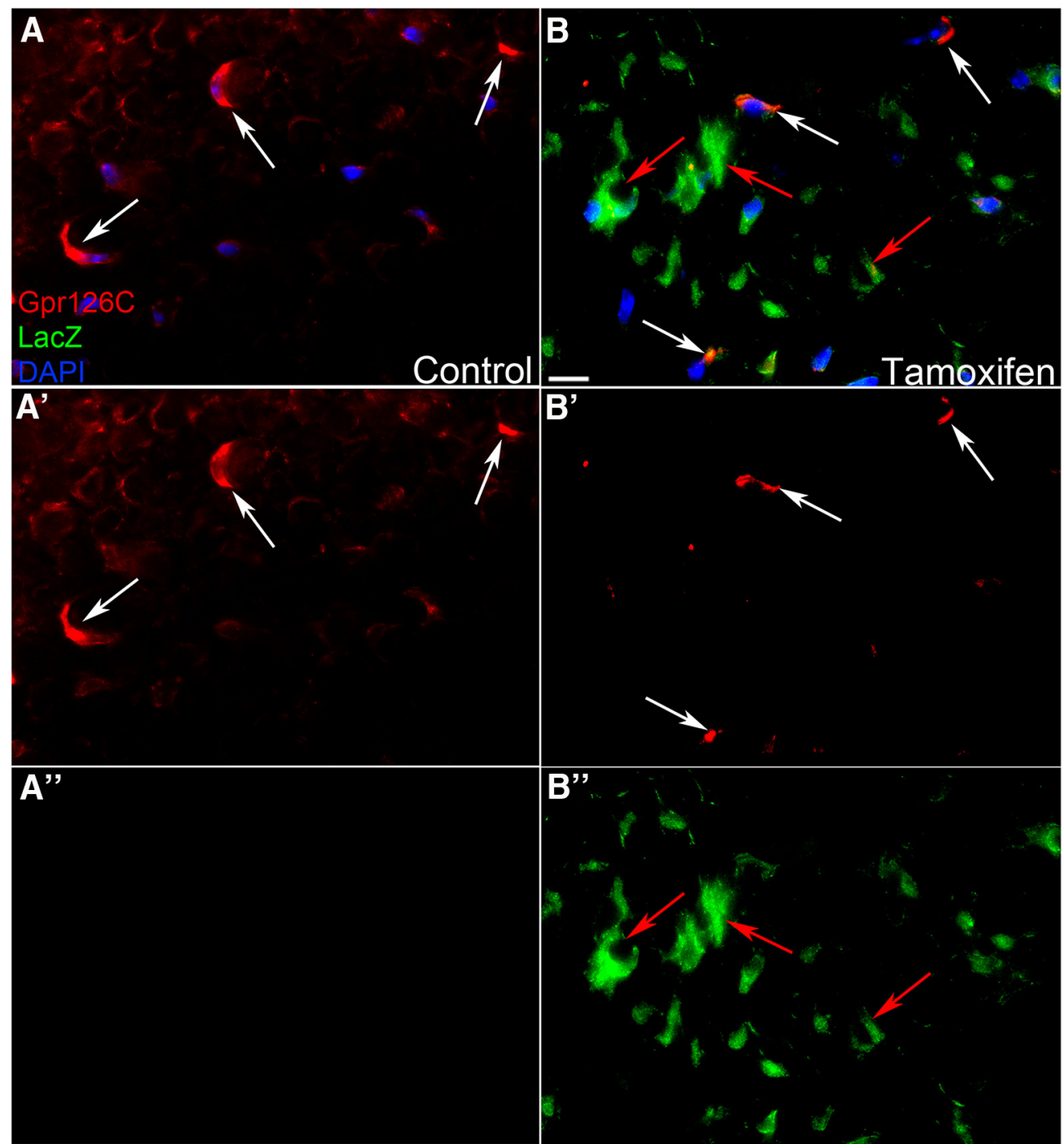

C

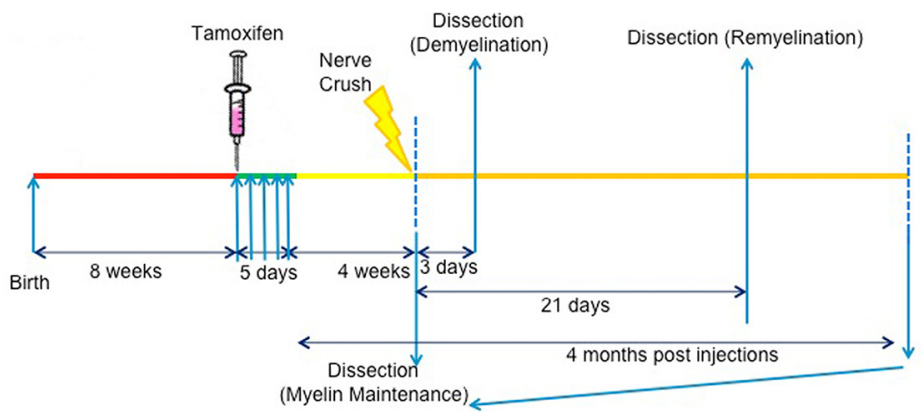

Figure 1. PLP Pre-ERT2 drives recombination of Gpr126 in mature SCS. $\boldsymbol{A}, \boldsymbol{B}, \mathrm{IHC}$ shows Gpr126 protein levels in icK0 mice 4 weeks after control $(\boldsymbol{A})$ or tamoxifen $(\boldsymbol{B})$ injections. $\boldsymbol{A}-\boldsymbol{A}^{\prime \prime}, \mathrm{Gpr} 126$ (red) is observed in SCs from control-injected sciatic nerve (arrows), but LacZ (green) is not, indicating a lack of (re activity. $\boldsymbol{B}-\boldsymbol{B}^{\prime \prime}$, Gpr126 (red) is not observed in recombined LacZ(+) (green) SCs (red arrows), demonstrating that $P L P^{\text {Cre-ERT2 }}$ can effectively delete Gpr 126 from mature SCS. Some Gpr126(+) cells are observed (white arrows), but do not costain for LacZ, indicating that Cre was not active. DAPI (blue) labels nuclei. Scale bar: (in $\boldsymbol{B}) \boldsymbol{A}, \boldsymbol{B}, 50 \mu \mathrm{m}$. C, Schematic representation of experimental approach in ick0 mice.

injected icKO mice 4 weeks after injection. We did not observe differences between the two groups in the levels of myelin basic protein (MBP) by IHC (Fig. $2 A, B ; N=3$ for each group), and LacZ staining again demonstrated robust Cre activity in tamoxifen-injected animals (Fig. 2A,B). Consistent with this observation, toluidine blue staining of semithin $(200-300 \mathrm{~nm}) \mathrm{sec}-$ tions showed no obvious differences in morphology between tamoxifen-injected and control-injected icKO animals at 4 weeks (Fig. 2C,D;N=3 for each group). We next counted the number of SC nuclei 4 weeks after injection to determine whether the SC number is affected by the loss of Gpr126 and did not observe any significant difference in the number of SC nuclei (Fig. 2G; $N=3$ for each group). Quantitative reverse-transcription PCR (qPCR) analysis on the sciatic nerves for mature SC markers (Sox10, Oct6, and $M b p$ ) revealed no significant change in the expression levels of these genes 4 weeks after injection (Fig. $2 H$ ). Finally, ultrastructural analyses by TEM further demonstrated that there are no differences in myelin ultrastructure or thickness in 

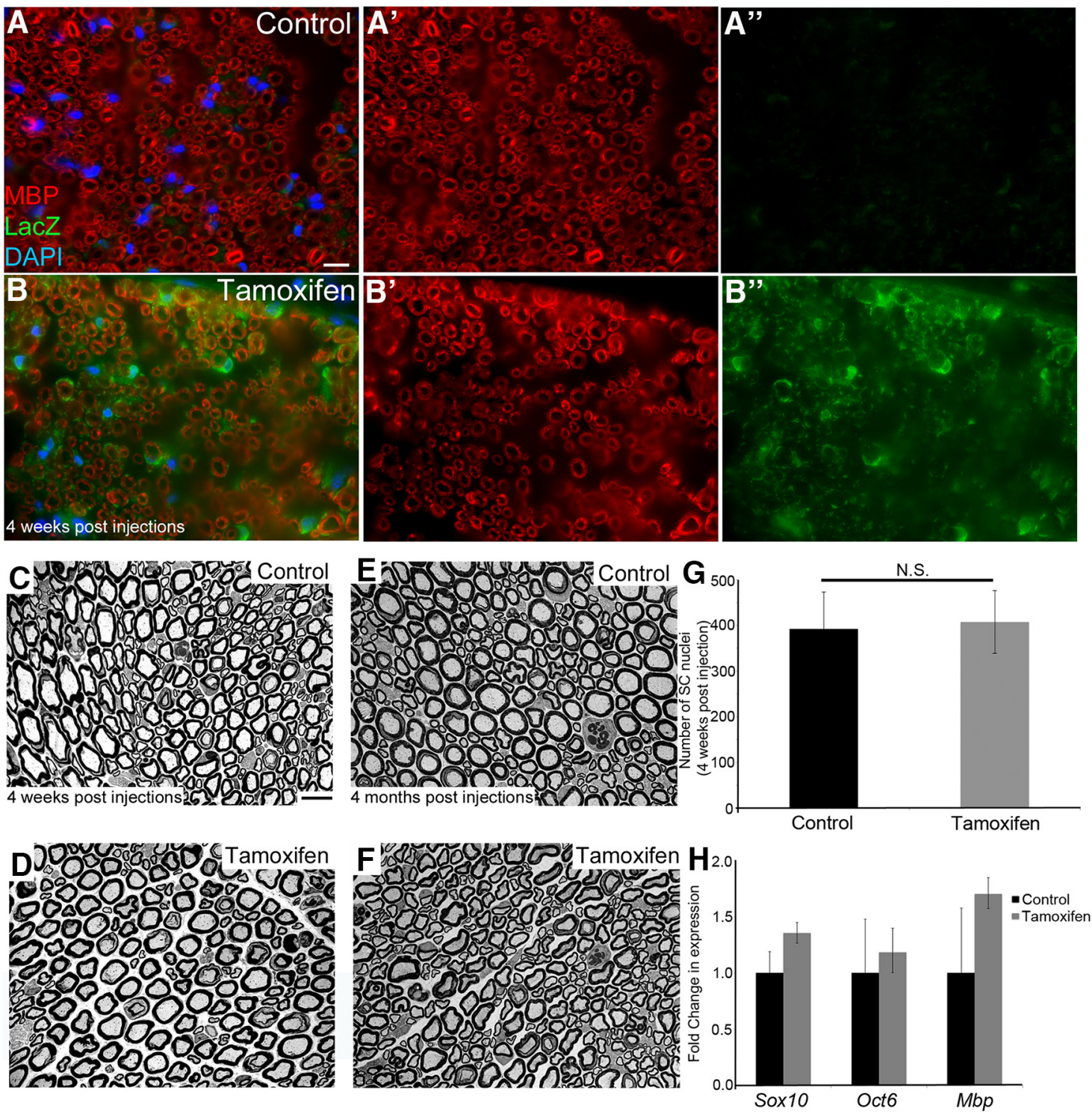

Figure 2. Gpr126 is dispensable for maintenance of MBP protein levels and gross myelin morphology up to 4 months. $\boldsymbol{A}-\boldsymbol{B}^{\prime \prime}, \mathrm{IHC}$ of sciatic nerve cross sections stained with MBP (red), LacZ (green), and DAPI (blue) 4 weeks following final control $\left(\boldsymbol{A}-\boldsymbol{A}^{\prime \prime}\right)$ or tamoxifen $\left(\boldsymbol{B}-\boldsymbol{B}^{\prime \prime}\right)$ injections. Scale bar: (in $\left.\boldsymbol{A}\right), \boldsymbol{A}-\boldsymbol{B}^{\prime \prime}, 50 \mu \mathrm{m}$. $\boldsymbol{C}-\boldsymbol{F}$, Toluidine blue stained semithin sections of control-injected $(\boldsymbol{C}, \boldsymbol{E})$ and tamoxifen-injected $(\boldsymbol{D}, \boldsymbol{F})$ animals reveal no gross differences 4 weeks $(\boldsymbol{C}, \boldsymbol{D})$ or 4 months $(\boldsymbol{E}, \boldsymbol{F})$ following the final injections. Scale bar: (in $\boldsymbol{C}) \boldsymbol{C}-\boldsymbol{F}, 20 \mu \mathrm{m}$. $\boldsymbol{G}$, Number of $S \boldsymbol{C}$ nuclei is not significantly different in tamoxifen-injected animals compared with controls 4 weeks after injection. $H$, qPCR 4 weeks after tamoxifen injection reveals that expression of key SC differentiation genes (Sox $10,0 c t 6$, $M b p)$ is not significantly altered between the two groups. Error bars are shown as \pm SD.

tamoxifen-injected versus control-injected icKO mice 4 weeks following the final injection (Fig. $3 A, C, E, G ; N=3$ for each group, $p=0.19$, ANOVA). These data support the notion that Gpr126 is not required for myelin maintenance up to 1 month, consistent with previous observations in zebrafish (Glenn and Talbot, 2013).

To determine whether deletion of Gpr126 from SCs affects longer-term myelin maintenance, we expanded our analysis to 4 months after tamoxifen injections. Similar to 4 weeks after injection, MBP levels and nerve morphology are not affected in icKO Gpr126 mutants compared with controls as assessed by IHC (data not shown) and toluidine blue-stained semithin sections, respectively (Fig. $2 E, F ; N=3$ for each group). Moreover, TEM analyses again revealed no obvious differences in myelin ultrastructure or thickness in tamoxifen-injected versus control-injected icKO mice (Fig. $3 B, D, F, H ; N=3$ for each group, $p=0.13$, ANOVA). Together, these data suggest that Gpr126 is dispensable for my- elin maintenance up to 4 months; thus, we were able to perform nerve-injury studies without confounding effects on Gpr126dependent PNS maintenance.

\section{Remyelination is impaired in inducible Gpr126 mutants}

To further dissect the function of Gpr126 in mature nerve, we next investigated its necessity in remyelination following nerve injury. To this end, we crushed the sciatic nerves of tamoxifeninjected or control-injected icKO mice 4 weeks after the last injection and analyzed the nerves at $21 \mathrm{dpi}(N=3$ for each group). By this time point in control nerves, myelin debris has been largely cleared, axons have regrown, and redifferentiated SCs are robustly remyelinating regenerated axons (Akassoglou et al., 2002). To ensure valid comparisons between the experimental groups, we marked the crush site at the time of injury with powdered carbon, and we analyzed distal sciatic nerve segments at the same distance from the crush site $(5 \mathrm{~mm})$. 

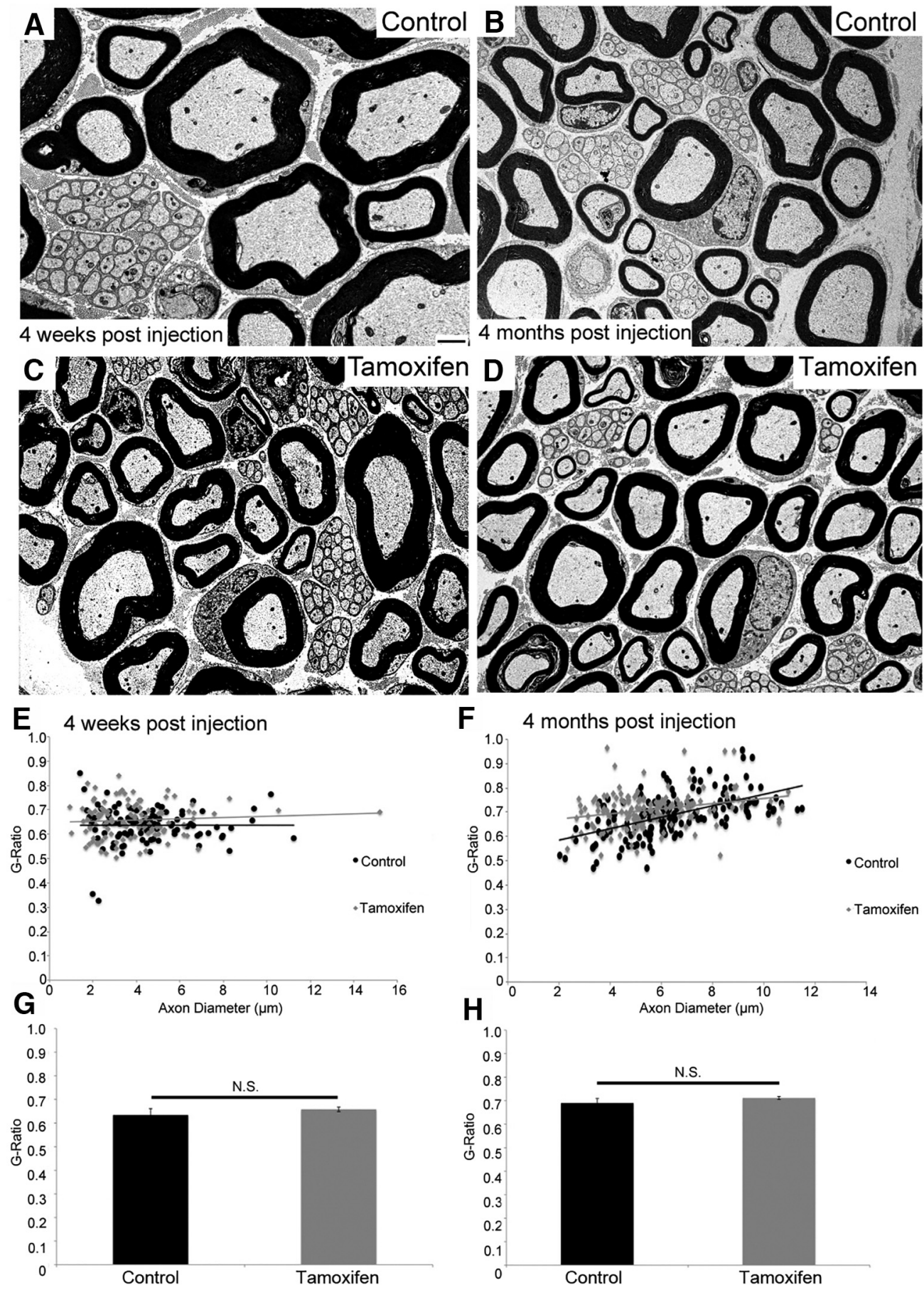

Figure 3. Gpr126 is dispensable for myelin maintenance up to 4 months. $\boldsymbol{A}-\boldsymbol{D}$, TEM micrographs of sciatic nerves from control-injected $(\boldsymbol{A}, \boldsymbol{B})$ and tamoxifen-injected $(\boldsymbol{C}, \boldsymbol{D})$ ick0 animals 4 weeks $(\boldsymbol{A}, \boldsymbol{C})$ and 4 months $(\boldsymbol{B}, \boldsymbol{D})$ following the final injection. No gross differences were observed in either treatment or time point. Scale bar: (in $\boldsymbol{A}) \boldsymbol{A}-\boldsymbol{D}, 2 \mu \mathrm{m}$. $\boldsymbol{E}-\boldsymbol{H}, \mathrm{Quantification}$ of g-ratio in control-injected (black) and tamoxifen-injected (gray) ick0 animals at 4 weeks $(\boldsymbol{E}, \boldsymbol{G})$ and 4 months $(\boldsymbol{F}, \boldsymbol{H})$ following the final injection. G-ratio quantification reveals no significant difference between the two groups 4 weeks after injections ( $p=0.19$, ANOVA) or at 4 months after injections ( $p=0.13$, ANOVA). Error bars are shown as \pm SD.

Toluidine blue-stained semithin sections and TEM analyses show that nerves from control-injected icKO mice are robustly remyelinated with little myelin debris persisting (Fig. $4 A, C, E)$. In contrast, remyelination is significantly impaired in sciatic nerves from tamoxifen-injected icKO mice as assessed by toluidine blue-stained semithin sections (Fig. 4B). TEM analyses further revealed many defects at the ultrastructural level in tamoxifeninjected icKO mice at $21 \mathrm{dpi}$ (Fig. $4 D$ ), including significantly more myelin debris (Fig. $4 D$, black arrows, $E ; p=5.7 \times 10^{-13}$,
Student's $t$ test), large-caliber axons $(>1 \mu \mathrm{m})$ in bundles (Fig. $4 D$, asterisks), aberrant SC cytoplasmic protrusions (Fig. $4 D$, white arrows), and fewer myelinated axons (Fig. $4 F ; p=2.3 \times$ $10^{-8}$, Student's $t$ test). G-ratio analyses revealed that the remyelinated axons observed in the tamoxifen-injected icKO animals have thinner myelin (i.e., higher g-ratios) compared with control-injected animals (Fig. 4G,H; $p=0.00006$, ANOVA). Importantly, IHC staining with MBP and LacZ showed that myelin debris-like figures were associated with $\mathrm{LacZ}(+)$ SCs (Fig. $5 B$, 

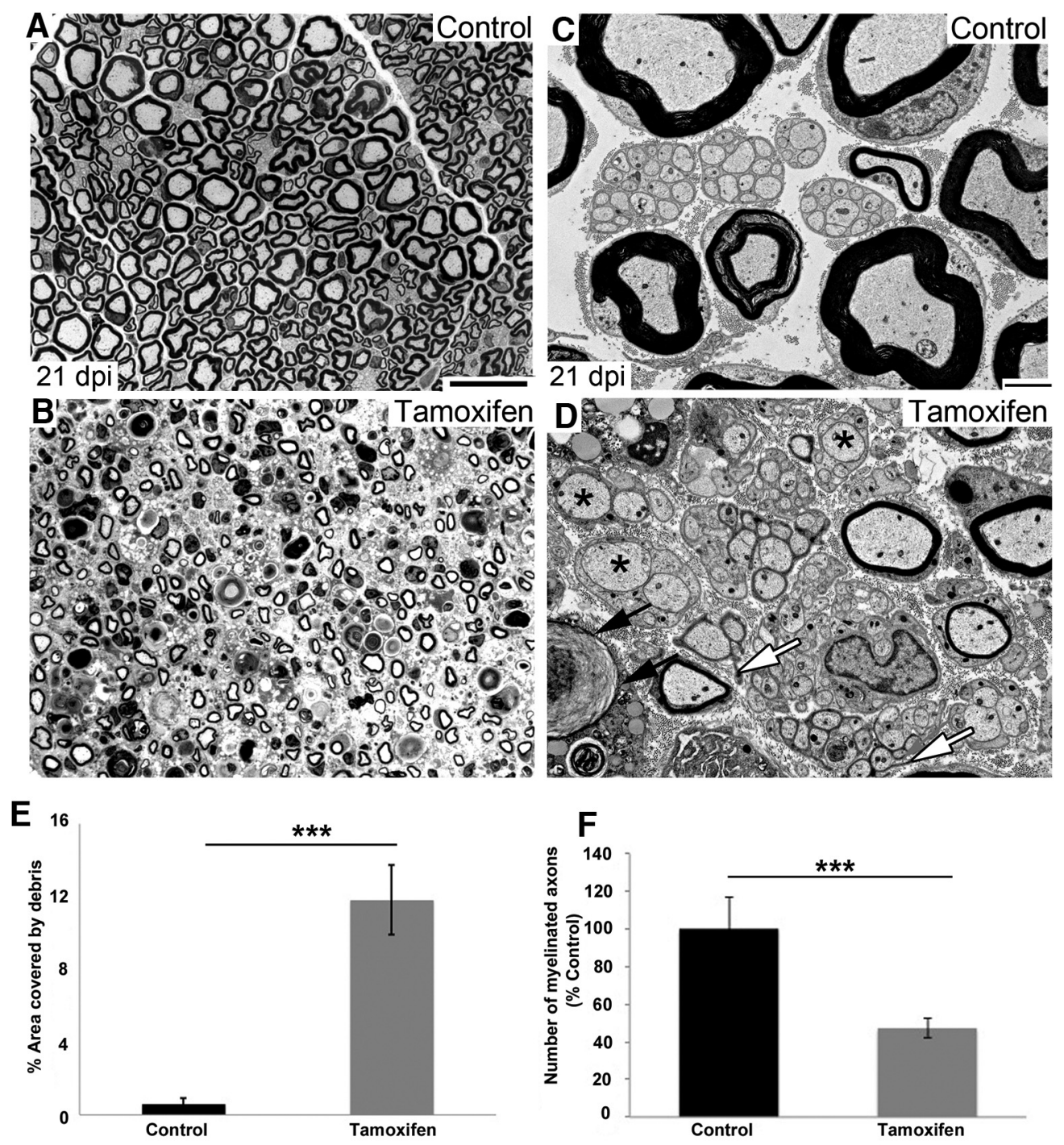

G
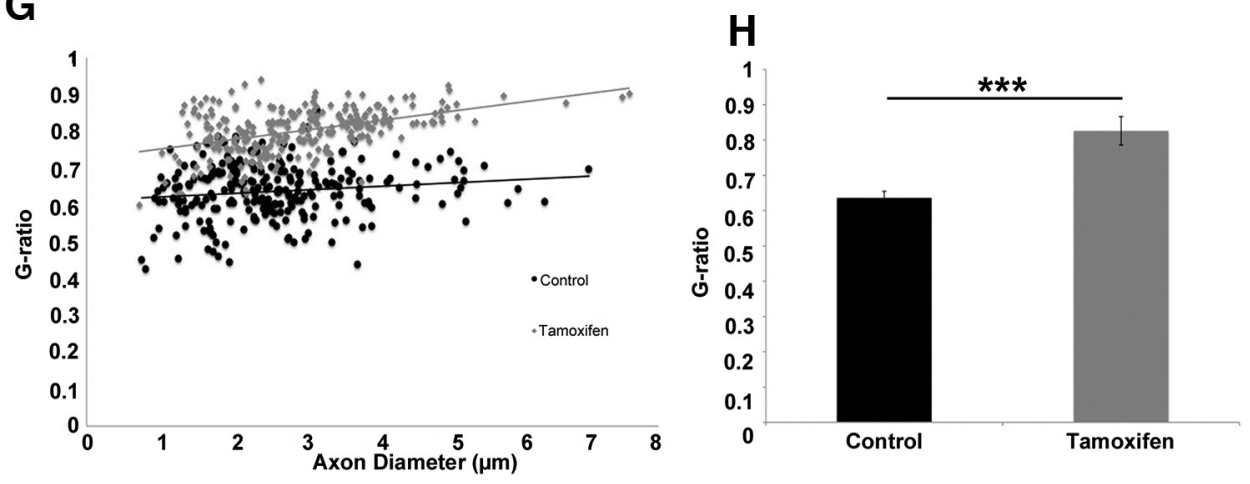

Figure 4. Remyelination is impaired in inducible Gpr126 mutants. $A, B$, Toluidine blue-stained semithin sciatic nerve sections reveal impaired remyelination in tamoxifen-injected icK0 animals (B) compared with control animals (A) 21 dpi. Scale bar: (in $\boldsymbol{A}) \boldsymbol{A}, \boldsymbol{B}, 20 \mu \mathrm{m}$. C, D, TEM micrographs of control-injected ( $\boldsymbol{C}$ ) or tamoxifen-injected (D) ick0 sciatic nerves at $21 \mathrm{dpi}$. Axons in control nerves are well myelinated. In tamoxifen-injected ick0 sciatic nerves, myelin debris is evident ( $\boldsymbol{D}$, black arrows), few axons are myelinated, large caliber axons are observed in bundles ( $\boldsymbol{D}$, asterisks), and SC cytoplasmic protrusions are observed ( $\boldsymbol{D}$, white arrows). Scale bar: (in $\boldsymbol{C}) \boldsymbol{C}, \boldsymbol{D}, 2 \mu \mathrm{m} . \boldsymbol{E}, \boldsymbol{F}$, Quantification of nerve abnormalities in control-injected (black) versus tamoxifen-injected (gray) icKO animals at $21 \mathrm{dpi}$. $\boldsymbol{E}$, More area is covered by myelin debris in tamoxifen-injected icKO mice compared with controls $\left(p=5.8 \times 10^{-13}\right.$, Student's $t$ test). $\boldsymbol{F}$, Fewer axons are myelinated in tamoxifen-injected compared with control-injected icK0 animals $\left(p=2.3 \times 10^{-08}\right.$, Student's $t$ test). $\mathbf{G}, \boldsymbol{H}$, G-ratio analyses show that when remyelination occurs in tamoxifen-injected animals, the myelin sheaths are thinner than in control-injected animals ( $p=0.003$, ANOVA). Error bars are shown as \pm SD.

arrowheads), while myelin rings with normal morphology were not associated with $\operatorname{LaCZ}(+)$ SCs (Fig. 5B, asterisks). This indicates that Gpr126(+) SCs are capable of remyelination, while Gpr126(-) SCs are not, supporting the model that Gpr126 is required SC-autonomously for remyelination. To more conclusively demonstrate that the $\operatorname{LacZ}(+)$ cells we observed in tamoxifen-injected animals are incapable of remyelination, we performed bluo-gal staining on the sciatic nerves at 21 dpi before 

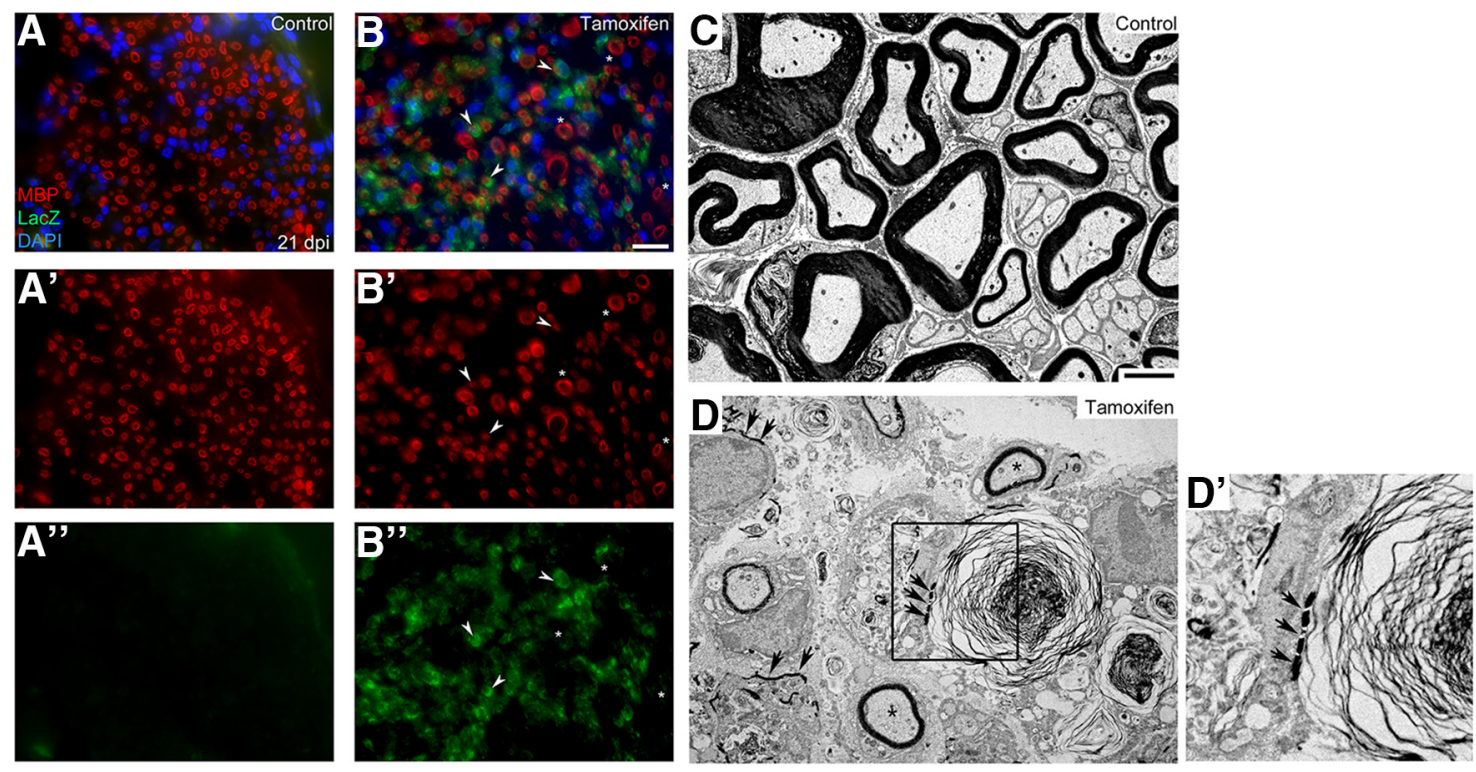

Figure 5. Gpr126 in SCs is required for remyelination at 21 dpi. $\boldsymbol{A}, \boldsymbol{B}, \mathrm{IHC}$ of sciatic nerve cross sections at $21 \mathrm{dpi}$ in control-injected $(\boldsymbol{A})$ and tamoxifen-injected ( $\boldsymbol{B})$ animals stained with MBP (red), LacZ (green), and DAPI (blue). Robust MBP stain in control animals reveals that most myelin rings have normal morphology. In tamoxifen-injected animals, MBP stain with abnormal morphology is associated with LacZ(+) SCs (arrowheads), while MBP stain with normal morphology is associated with LaCZ(-) SCs (asterisks). C- $\boldsymbol{D}^{\prime}$, Bluo-gal EM staining of nerves at 21 dpi reveals that the myelinated axons observed in tamoxifen-treated nerves are associated with bluo-gal $(-)$ SCs that therefore lack Cre activity $(\boldsymbol{D}$, asterisks). In contrast, bluo-gal ( + ) SCS (identified by deposition of electron dense bluo-gal reaction residue, arrowheads) have persistent myelin debris. Box in $\boldsymbol{D}$ shown magnified in $\boldsymbol{D}^{\prime}$. Scale bars: (in $\left.\boldsymbol{B}\right) \boldsymbol{A}-\boldsymbol{B}^{\prime \prime}, 50 \mu \mathrm{m}$; (in $\left.\boldsymbol{C}\right) \boldsymbol{C}, \boldsymbol{D}, 2 \mu \mathrm{m}$.

TEM analysis. This causes bluo-gal crystals to form in LacZ(+) cells, which can be visualized by TEM (Aoyama et al., 2004). This approach showed that bluo-gal(+) SCs (Fig. 5D, $D^{\prime}$, black arrows) are filled with myelin debris and have not remyelinated, whereas we never observed bluo-gal crystals in SCs that have remyelinated (Fig. 5D, asterisks).

To determine whether remyelination impairments in tamoxifeninjected icKO animals are transient, we analyzed the sciatic nerves from control-injected and tamoxifen-injected icKO mice at $35 \mathrm{dpi}$ (Fig. 6). We again performed bluo-gal staining before TEM analysis to identify SCs with or without Cre activity. We observed that even at $35 \mathrm{dpi}$, remyelination was impaired in tamoxifen-injected animals (Fig. 6B). There were some myelinated axons present (Fig. 6B, asterisks), but these were always associated with bluo-gal(-) SCs. In contrast, axons associated with bluo-gal( + ) SCs were unmyelinated, often with myelin debris still present (Fig. 6B, arrows). Together, these data indicate that Gpr126 is required autonomously in SCs for remyelination.

\section{Gpr126 is not required for demyelination or c-Jun elevation} in repair SCs following injury

Consistent with the essential role of Gpr126 in SC developmental myelination, we propose that this aGPCR is similarly required for remyelination following injury. Beyond this role, however, we note that cellular responses to nerve injury and subsequent regeneration are complex and highly controlled. Thus, the impaired remyelination we observe in inducible Gpr126 mutants could also in part be attributable to several, nonmutually exclusive causes. Following nerve injury, SCs transform into dedicated repair cells that degrade myelin by a selective form of autophagy termed "myelinophagy" (Gomez-Sanchez et al., 2015), macrophages are recruited to aid in myelin debris clearance, and axons must regrow through SC/basal lamina tubes found distal to the injury (Chen et al., 2007). Therefore, we sought to further investigate each stage of injury and repair to define the function(s) of Gpr126 in peripheral regeneration. First, we analyzed nerves at 3 dpi by TEM and IHC staining. At this early time point after injury, robust demyelination, repair SC generation, and myelin/ axonal debris clearance should be evident (Jessen and Mirsky, 2008; Arthur-Farraj et al., 2012; Jessen et al., 2015). Neither toluidine blue-stained semithin sections nor TEM micrographs revealed overt differences between tamoxifen-injected or control-injected icKO mice (Fig. 7A-D), and both groups had similar amounts of myelin debris (Fig. $7 E ; N=3, p=0.91$, Student's $t$ test). These data suggest that Gpr126 is not required in SCs for demyelination following injury.

Next, we examined the ability of SCs lacking Gpr126 to elevate c-Jun. After injury, this transcription factor is required in SCs for downregulation of mature SC genes, for transformation into repair SCs, and c-Jun can be used as a molecular marker of repair SCs (Arthur-Farraj et al., 2012; Jessen et al., 2015). We observed no differences in c-Jun $(+)$ nuclei by IHC in control-injected versus tamoxifen-injected animals at $3 \mathrm{dpi}$ (Fig. $8 A-C ; N=3, p=$ 0.85 , Student's $t$ test). Additionally, Ki67 staining revealed that proliferation was not affected in control-injected versus tamoxifen-injected icKO mice at $3 \mathrm{dpi}$ (data not shown). Western blot analysis demonstrated that c-Jun was indeed elevated in tamoxifen-injected icKO nerves at $3 \mathrm{dpi}$, although levels were slightly lower than those of control-injected nerves (Fig. $8 D, E$; $N=4, p=0.02$ ). Tamoxifen-injected icKO animals possess both mutant and unrecombined wild-type SCs, which could affect quantitative analysis of protein levels. Therefore, we next examined c-Jun levels in SC-specific conditional knock-out Gpr126 $6^{f l f l} ; \mathrm{Dhh} \mathrm{Cre}^{\mathrm{C}+}$ mice in which Gpr126 is deleted at $\sim \mathrm{E} 12.5$ (Mogha et al., 2013). The Gpr126 ${ }^{f l f l} ; D_{h h^{C r e}+}$ mice are hereafter referred to as "cKO" animals. qPCR for the transcription factor Sox10, which marks all SCs, revealed no significant differences between control and $\mathrm{cKO}$ animals $3 \mathrm{dpi}$ (Fig. $8 F$ ). Western blot analyses showed that, without injury, c-Jun levels in some cKO mice were slightly higher than in wild-type siblings (Fig. 8G, H; $N=6, p=0.003$; see below). Importantly, however, upregulation of total c-Jun is not affected negatively in cKO animals at 3 

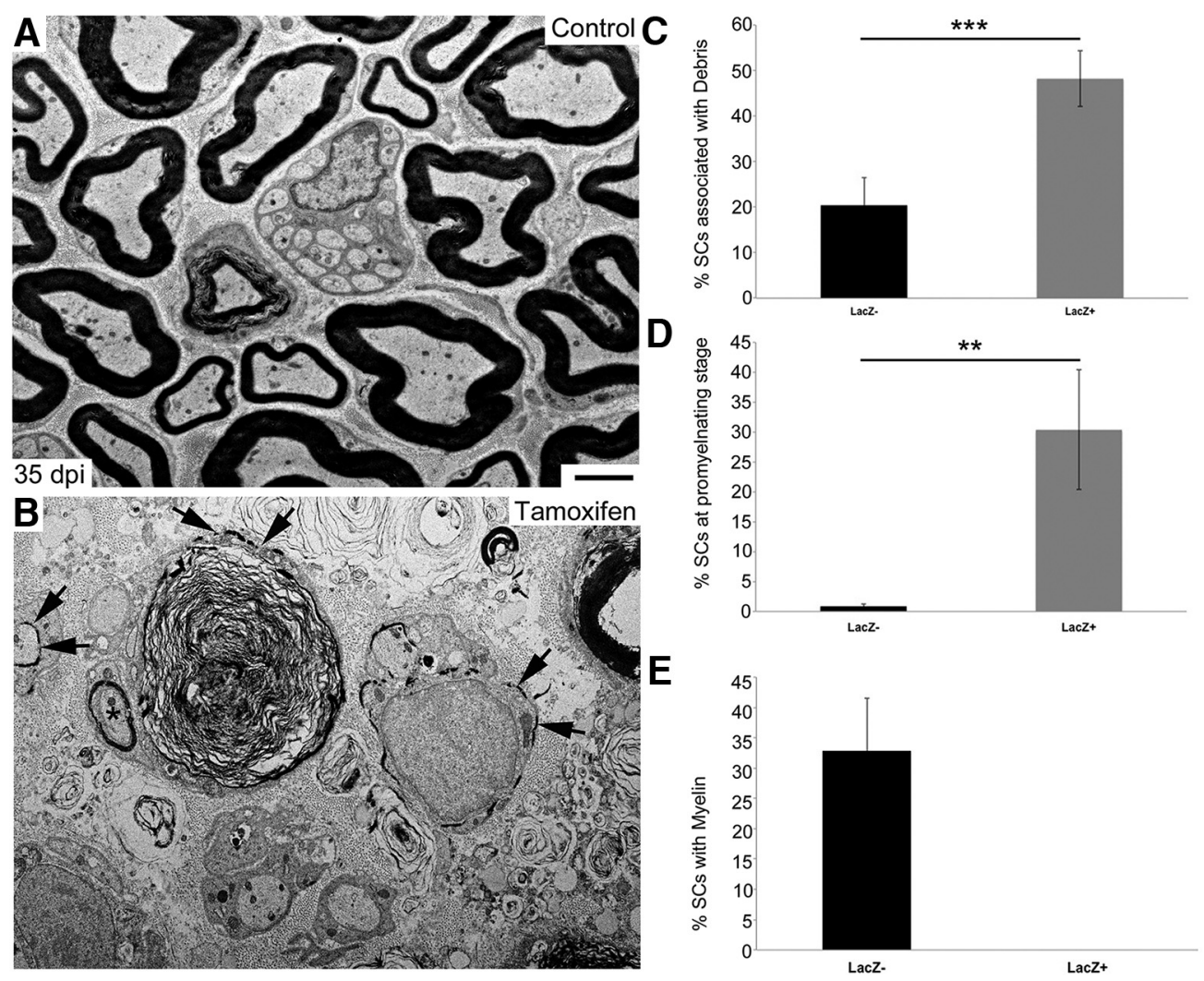

Figure 6. Gpr126 in SCs is required for remyelination at 35 dpi. $\boldsymbol{A}, \boldsymbol{B}$, TEM images at $35 \mathrm{dpi}$ of sciatic nerve cross sections from control-injected $(\boldsymbol{A})$ or tamoxifen-injected $(\boldsymbol{B})$ mice. Myelin debris persists and is associated only with SCs possessing bluo-gal crystals (B, arrows). In contrast, SCs lacking bluo-gal crystals are associated with myelin (B, asterisk). $\boldsymbol{C}-\boldsymbol{E}$, Quantifications show the percentage LacZ(+) (gray bars) or LacZ( -$)$ (black bars) SCs with the indicated characteristics. C, More LaCZ(+) SCs are associated with myelin debris compared with LacZ( -$)$ SCS $(p=0.002$, Student's $t$ test). $\boldsymbol{D}$, More LacZ(+) SCS are observed at the promyelinating stage than LacZ( -$)$ SCS $(p=0.007$, Student's $t$ test). E, Only LaCZ( $)$, and never LacZ( +$)$ SCS, are observed at the myelinating stage. $N=4$.
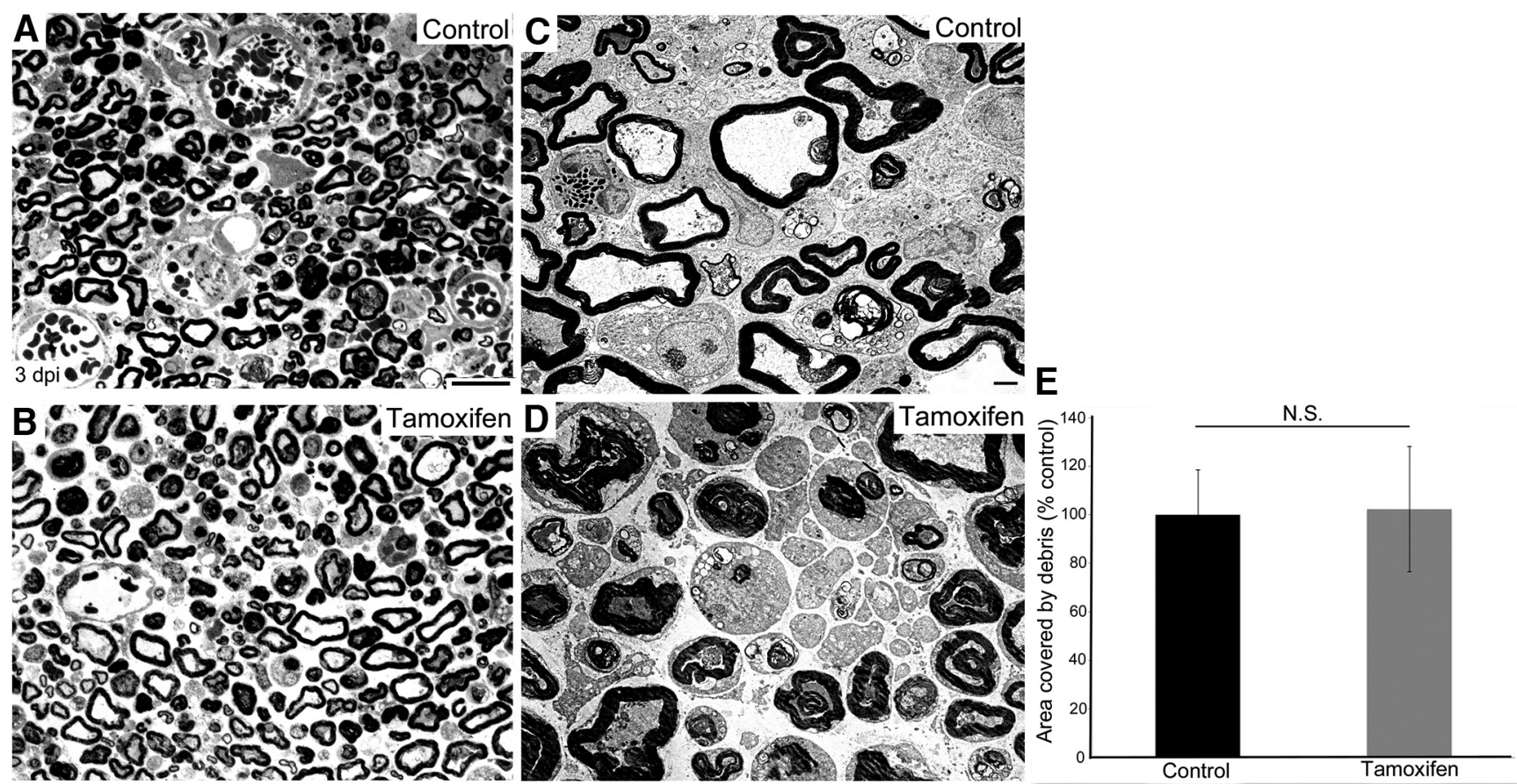

Figure 7. Demyelination is not impaired in inducible Gpr126 mutants following injury. $A, B$, Toluidine blue-stained semithin sciatic nerve sections reveal grossly equal demyelination in tamoxifen-injected icK0 animals $(\boldsymbol{B})$ compared with control animals $(\boldsymbol{A})$ at 3 dpi. Scale bar: (in $\boldsymbol{A}) \boldsymbol{A}, \boldsymbol{B}, 50 \mu \mathrm{m}$. $\boldsymbol{C}, \boldsymbol{D}$, TEM micrographs of control-injected $(\boldsymbol{C})$ or tamoxifen-injected $(\boldsymbol{D})$ icKO sciatic nerves at 3 dpi. Scale bar: (in $C) C, D, 2 \mu \mathrm{m}$. E, Quantification reveals no significant differences in the area covered by myelin debris in control-injected (black bar) versus tamoxifen-injected (gray bar) icK0 animals ( $p=0.914$, Student's $t$ test). Error bars are shown as \pm SD. 

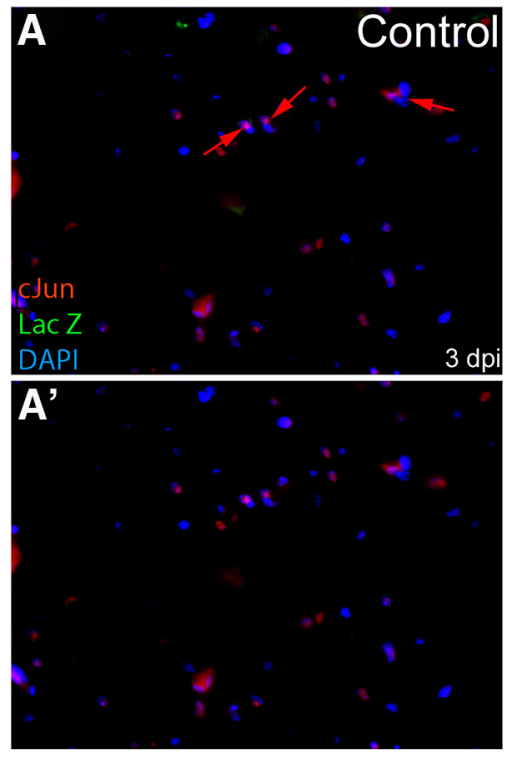

D

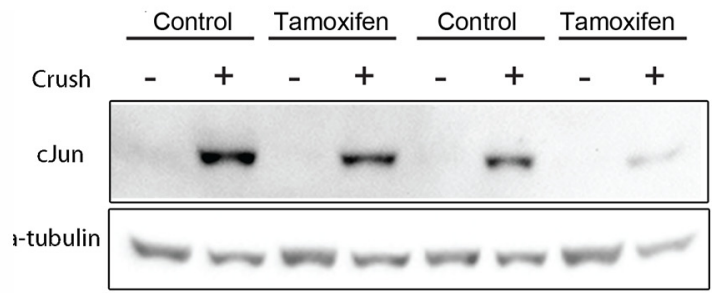

$\mathbf{F}$
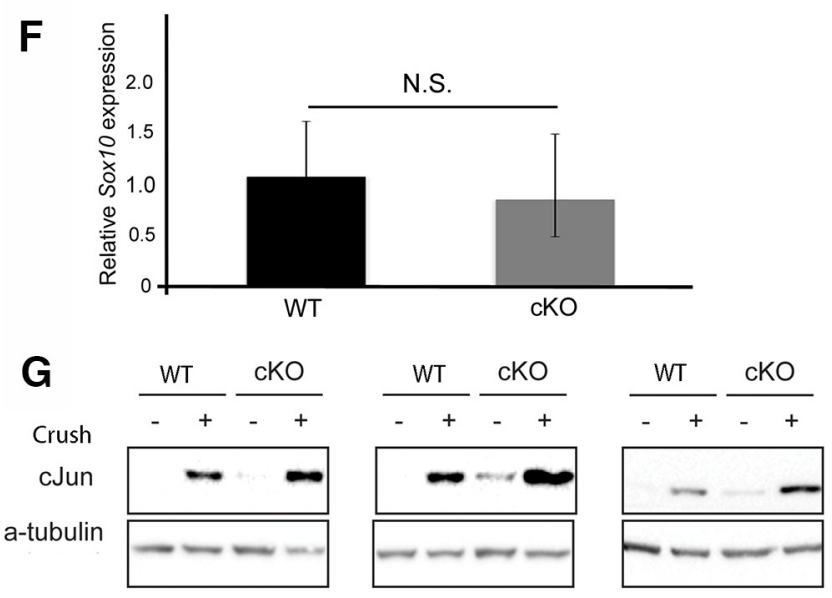
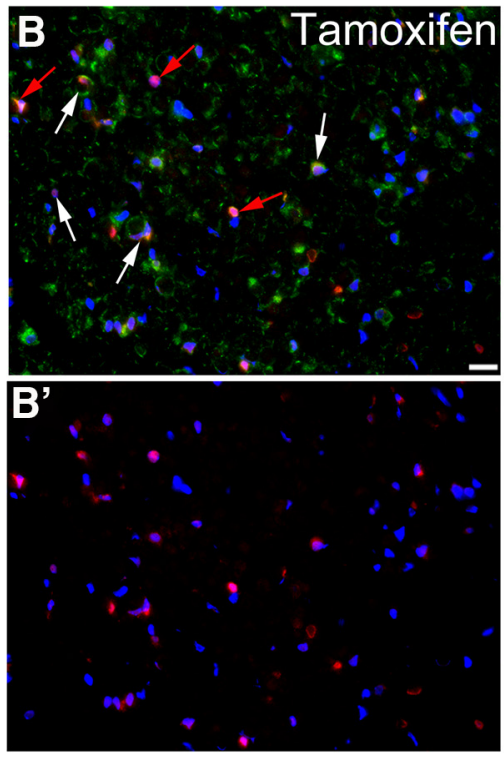

C

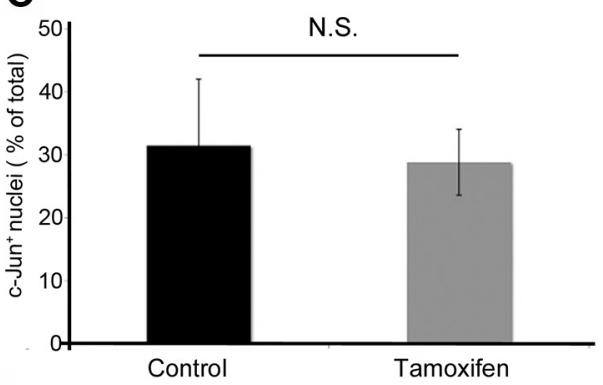

E

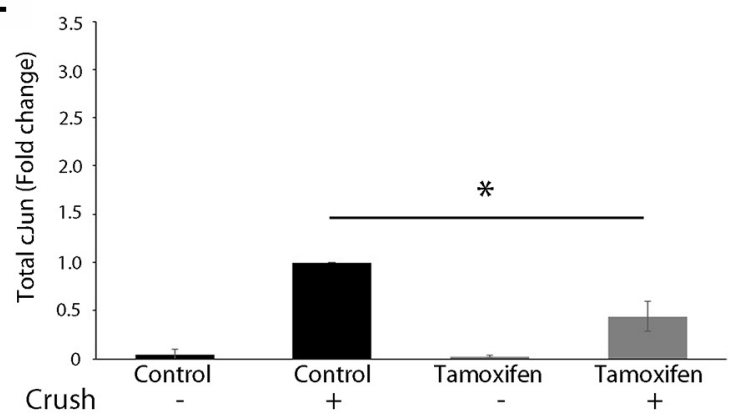

H

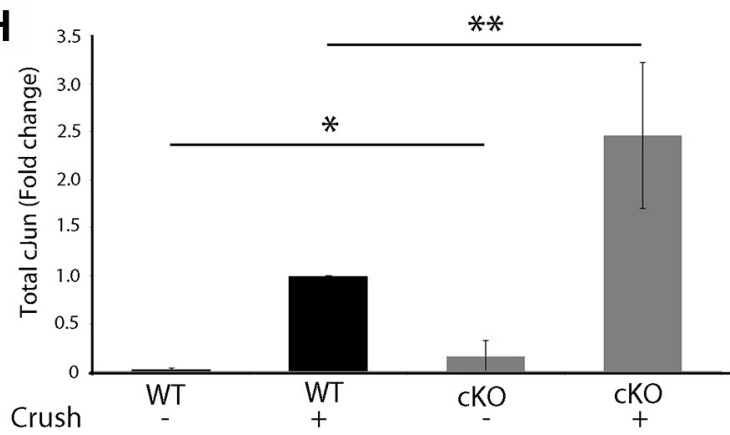

Figure 8. Gpr126 is not required for c-Jun induction in SCs following injury. $A-B^{\prime}, I H C$ of sciatic nerve cross sections at 3 dpi in control-injected $\left(\boldsymbol{A}, \boldsymbol{A}^{\prime}\right)$ and tamoxifen-injected $\left(\boldsymbol{B}^{\prime}\right)$ animals stained with LacZ (green), $c-J u n($ red), and DAPI (blue). Both LacZ(+) (white arrows) and LacZ(-) (red arrows) SCs are c-Jun $(+)$, indicating that SCs upregulate $c-J u n$ normally in the presence or absence of Gpr126. Scale bar: (in $\boldsymbol{B}) \boldsymbol{A}-\boldsymbol{B}^{\prime}, 20 \mu \mathrm{m}$. C, Quantification reveals no difference in the number of $\mathrm{c}-J u n(+)$ nuclei in control-injected (black bar) versus tamoxifen-injected (gray bar) icK0 animals ( $p=0.85$, Student's $t$ test). $\boldsymbol{D}$, Western blot analysis of sciatic nerve without $(-)$ and with $(+)$ nerve injury shows that tamoxifen-injected icKO animals upregulate c-Jun at $3 \mathrm{dpi}$, although to a variably lesser extent than control-injected animals. Results from $N=2$ control and $N=2$ tamoxifen-injected animals are shown. $\boldsymbol{E}$, Quantification of c-Jun levels in control-injected (black bars) versus tamoxifen-injected (gray bars) icK0 nerves $3 \mathrm{dpi}$ ( \pm nerve crush). Results are quantified from $N=4$ controlinjected and $N=4$ tamoxifen-injected animals $[p=0.02$ control-injected $(+)$ nerve crush vs tamoxifen-injected $(+)$ nerve crush, Student's $t$ test $] . F$, qPCR analysis shows that Sox10 expression is not significantly different in wild-type (WT; black bar) versus SC-specific cKO Gpr126 ${ }^{f / f l} ;$ Dhh ${ }^{\text {(re+ }}$ mice (cK0 animals, gray bar; $p=0.93$, Student's $t$ test). G, Western blot analysis of cKO nerves compared with wild-type sibling (WT) nerves at 3 dpi reveals that c-Jun is upregulated in both groups after injury. Results from $N=3$ WT and $N=3 \mathrm{cKO}$ animals are shown. $\boldsymbol{H}$, Quantification of $\mathrm{c}-\mathrm{Jun}$ levels in WT (black bars) versus cKO (gray bars) nerves at $3 \mathrm{dpi}$ ( \pm nerve crush). Results are quantified from $N=6 \mathrm{WT}$ and $N=6 \mathrm{cKO}$ animals $[p=$ 0.001 , WT $(+)$ nerve crush vs cKO $(+)$ nerve crush, Student's $t$ test]. Error bars are shown as \pm SD.

dpi, and indeed levels were higher in these mutants compared with wild-type siblings (Fig. 8G,H; $N=6, p=0.001$, Student's $t$ test). Together, these data support the notion that Gpr126 is dispensable for acquisition of some characteristics of the repair SC, namely demyelination, proliferation, and c-Jun activation.
Gpr126 is required in SCs for macrophage recruitment to the peripheral nerve following injury

Although SCs themselves can clear significant myelin debris in the distal stump of injured peripheral nerves (Perry et al., 1995; Niemi et al., 2013; Gomez-Sanchez et al., 2015), blood-derived 


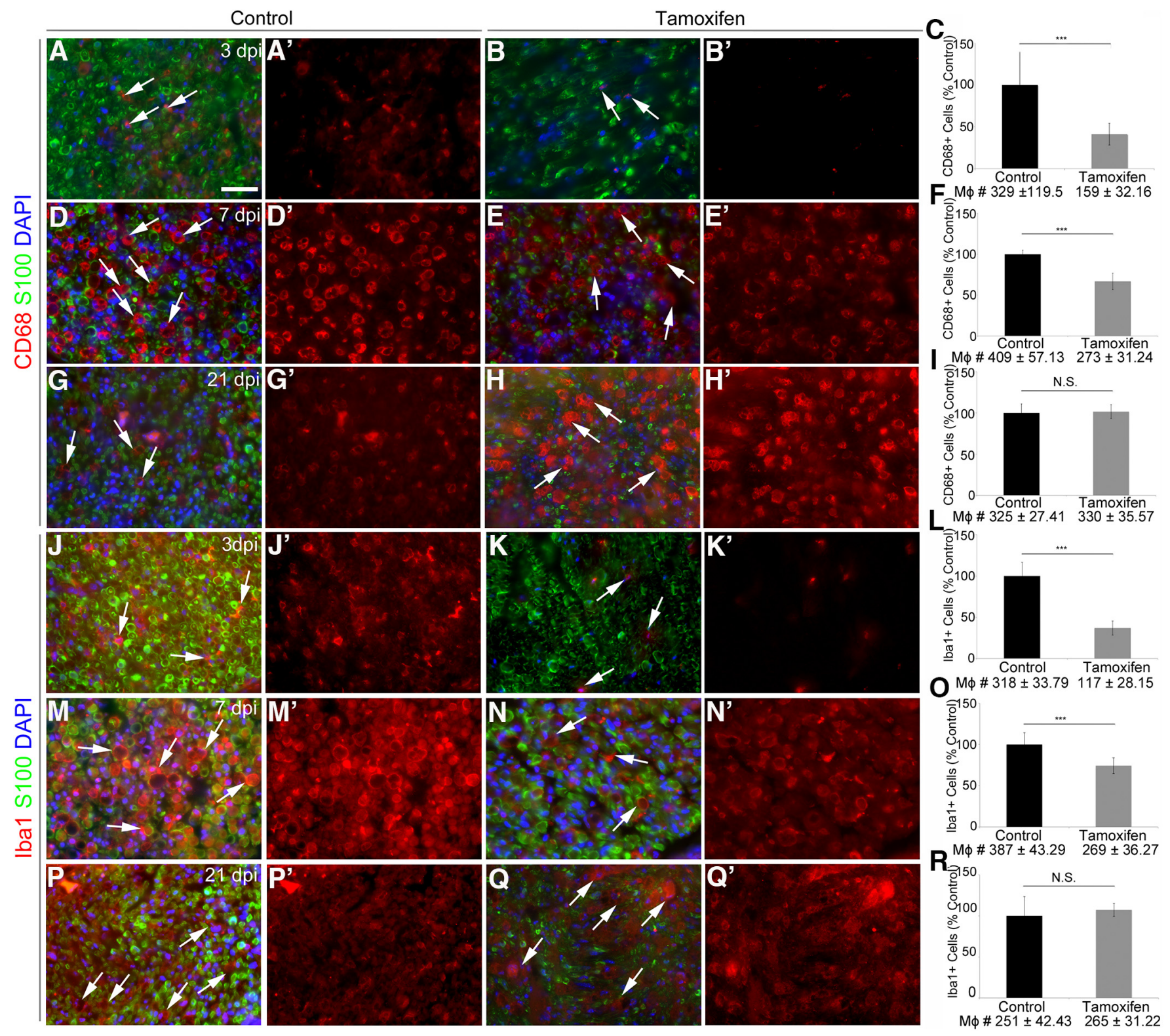

Figure 9. Macrophage recruitment is delayed in inducible Gpr126 mutants following injury. $\boldsymbol{A}, \mathrm{IHC}$ of sciatic nerve cross sections in control-injected $\left(\boldsymbol{A}, \boldsymbol{A}^{\prime}, \boldsymbol{D}, \boldsymbol{D}^{\prime}, \mathbf{G}, \mathbf{G}^{\prime}\right)$ and tamoxifen-injected

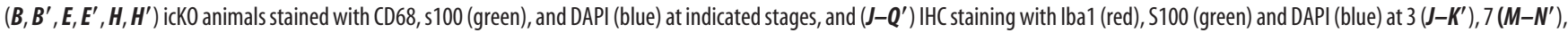
and $21 \mathrm{dpi}\left(\boldsymbol{P}-\boldsymbol{Q}^{\prime}\right)$, respectively. Scale bar: (in $\left.\boldsymbol{A}\right) \boldsymbol{A}-\boldsymbol{B}^{\prime}, \boldsymbol{D}-\boldsymbol{E}^{\prime}, \mathbf{G}-\boldsymbol{H}^{\prime}, \boldsymbol{J}-\boldsymbol{Q}^{\prime}, 50 \mu \mathrm{m} . \boldsymbol{C}, \boldsymbol{F}, \boldsymbol{I}, \mathbf{Q}$ uantification reveals a significant decrease in the number of CD68(+) macrophages in tamoxifen-injected (gray bar) versus control-injected (black bar) icK0 animals at $3\left(\boldsymbol{C} ; p=8.33 \times 10^{-05}\right.$, Student's t test) and $7 \mathrm{dpi}\left(\boldsymbol{F} ; p=1.99 \times 10^{-08}\right.$, Student's $t$ test), but not at $21 \mathrm{dpi}(\boldsymbol{I} ; p=0.82$, Student's $t$ test). $\boldsymbol{L}, \mathbf{O}, \boldsymbol{R}$, Similarly, the number of Iba $1(+)$ cells is significantly higher in control nerves at $3(\boldsymbol{L} ; p=0.0004$, Student's $t$ test) and $7 \mathrm{dpi}(\mathbf{0} ; p=0.0015$, Student's $t$ test), but not at 21 dpi $(\boldsymbol{R} ; p=$ 0.59 , Student's $t$ test). Error bars are \pm SD.

macrophages, which are in part recruited by SCs, are also key players in myelin debris clearance and peripheral nerve repair following injury (Martini et al., 2008; Chen et al., 2015). To test whether loss of Gpr126 in SCs impairs macrophage numbers, we performed IHC with macrophage markers (CD68 and Iba-1) on distal sciatic nerves of control-injected and tamoxifen-injected icKO mice at different time points after injury $(3,7$, and $21 \mathrm{dpi}$; Fig. 9). We counted the number of CD68 $(+)$ or Iba- $1(+)$ cells at all time points in control-injected versus tamoxifen-injected nerves. Quantification revealed a significant decrease in the number of $\mathrm{CD} 68(+)$ macrophages in tamoxifen-injected versus control-injected icKO animals at 3 (Fig. $9 C ; p=8.33 \times 10^{-05}$, Student's $t$ test) and 7 dpi (Fig. $9 F ; p=1.99 \times 10^{-08}$, Student's $t$ test), but not at $21 \mathrm{dpi}$ (Fig. 9I; $p=0.82$, Student's $t$ test). Simi- larly, the number of Iba1 $(+)$ cells is significantly higher in control nerves at 3 (Fig. $9 L ; p=0.0004$, Student's $t$ test) and 7 dpi (Fig. 9O; $p=0.0015$, Student's $t$ test), but not at 21 dpi (Fig. 9R; $p=0.59$, Student's $t$ test). To further dissect the role of SCderived Gpr126 in macrophage recruitment, we again used cKO mice in which Gpr126 is deleted in SCs from embryonic day 12.5 (Mogha et al., 2013). IHC analysis of cKO nerves at 3 dpi revealed that, similar to icKO nerves, macrophage numbers are significantly reduced compared with the wild-type nerves (Fig. 10A-F; $C, p=0.01$, Student's $t$ test; $F, p=0.00054$, Student's $t$ test). These data reveal an unexpected role for SC-derived Gpr126 in proper recruitment of macrophages following nerve injury.

Previous work has shown that after peripheral nerve injury, repair SCs secrete a variety of chemokines to recruit macrophages 


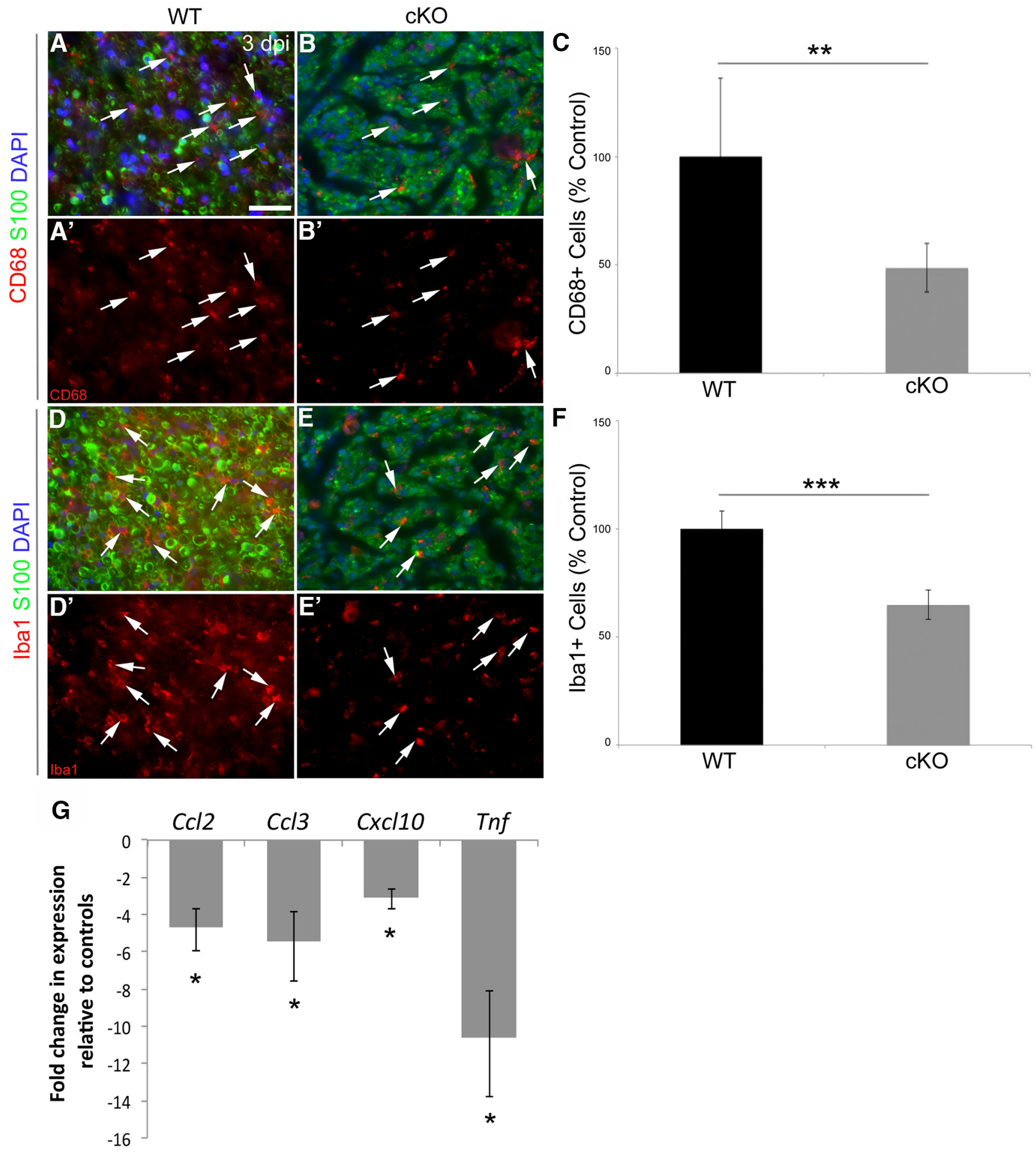

Figure 10. Macrophage recruitment and chemokine expression are impaired in conditional knock-out Gpr 126 mutants following injury. $\boldsymbol{A}-\boldsymbol{B}^{\prime}, \boldsymbol{D}-\boldsymbol{E}^{\prime}, \mathrm{IHC}$ for $C D 68\left(\boldsymbol{A}-\boldsymbol{B}^{\prime}\right)$ and lba1 $\left(\boldsymbol{D}-\boldsymbol{E}^{\prime}\right)$ show macrophages (red) in wild-type (WT; $\left.\boldsymbol{A}, \boldsymbol{A}^{\prime}, \boldsymbol{D}, \boldsymbol{D}^{\prime}\right)$ and $\mathrm{KKO}\left(\boldsymbol{B}, \boldsymbol{B}^{\prime}, \boldsymbol{E}, \boldsymbol{E}^{\prime}\right)$ nerves at 3 dpi. Scale bar: (in $\left.\boldsymbol{A}\right) \boldsymbol{A}-\boldsymbol{E}^{\prime}, 50 \mu \mathrm{m}$. $\boldsymbol{C}, \boldsymbol{F}$, Quantification of $\operatorname{CD68}(+)$ cells $(\boldsymbol{C})$ and lba1 $(+)$ cells $(\boldsymbol{F})$ reveals that the macrophage number is significantly decreased in CKO (gray bars) compared with WT (black bars). $\boldsymbol{C}, p=0.01$, Student's $t$ test; $\boldsymbol{F}, p=0.00054$, Student's $t$ test. $\boldsymbol{G}$, Chemokine expression is significantly reduced in Gpr126 CKO nerves at 3 dpi relative to controls $(C C l 2, p=0.0442 ; C(C / 3, p=0.0375, C x c 110, p=0.0244, \operatorname{Tnf}, p=0.0144$, Student's $t$ test $)$. Error bars are $\pm S D$.

to the injury site (Martini et al., 2008; Brosius Lutz and Barres, 2014). Therefore, we hypothesized that Gpr126 is required for chemokine expression after injury, and that the reduced infiltration of macrophages in Gpr126 mutants might be due to decreased chemokine expression by SCs. To begin to test this hypothesis, we compared the expression of a wide range of chemokines and their receptors between control and $\mathrm{CKO}$ nerves
$(N=3)$ at 3 dpi by qRT-PCR. For these experiments, we used cKO nerves because preliminary microarray analyses of icKO nerves ( \pm tamoxifen) indicated that there was not clear separation between experimental groups by PCA plot analysis, possibly due to the "contamination" of wild-type, unrecombined SCs in these tissues. Thus, cKO mice represent the best available tool with which to begin to dissect differential cytokine expression 

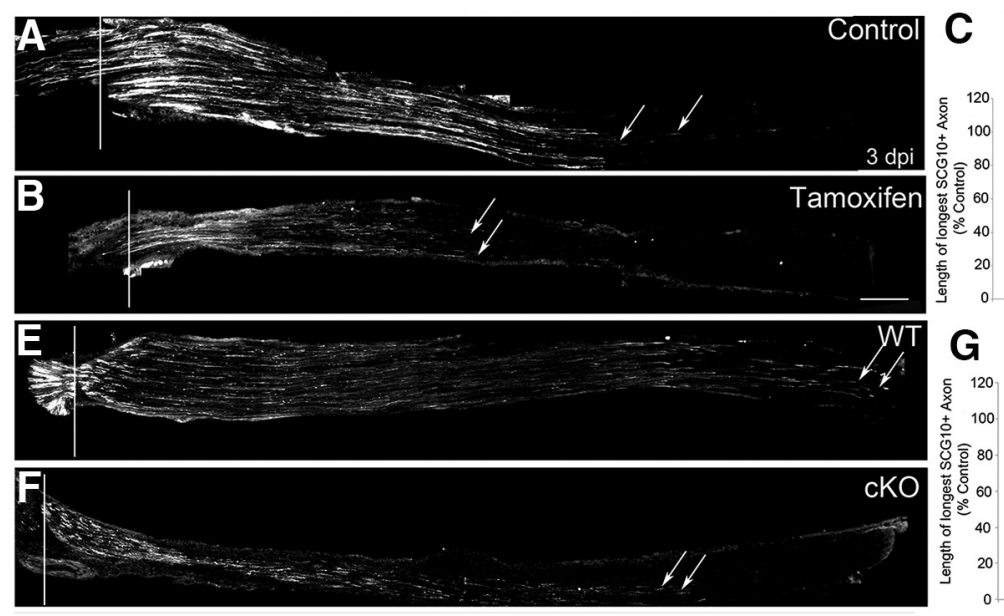

D
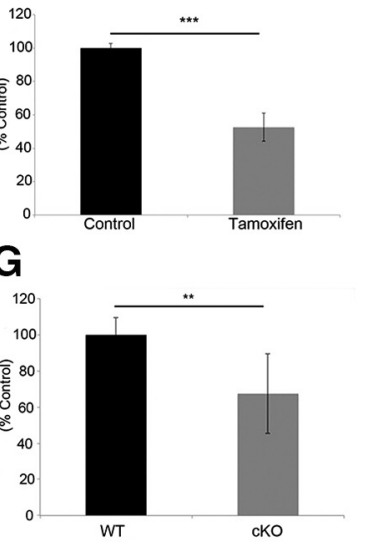

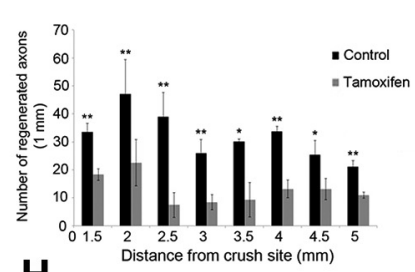

$\mathbf{H}_{\text {s. }}$

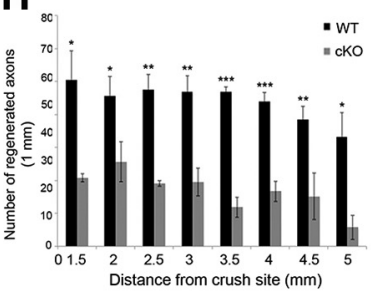

Figure 11. Axon regeneration is impaired when SCS lack Gpr126. A, B, IHC of longitudinal sections of crushed sciatic nerves stained with SCG10 at 3 dpi revealed that SCG10(+) axons extend farther in control-injected $(\boldsymbol{A})$ compared with tamoxifen-injected $(\boldsymbol{B})$ icK0 animals (white arrows). Crush sites are marked with white vertical lines. Scale bar: (in $\boldsymbol{B}) \boldsymbol{A}, \boldsymbol{B}, 500 \mu \mathrm{m}$. $\boldsymbol{C}, \boldsymbol{D}, \mathbf{Q}$ uantifications reveal that axon regeneration is significantly impaired in tamoxifen-injected compared with control-injected icK0 animals. $C$, Lengths of longest axons are shorter in tamoxifen-injected (gray bar) icK0 animals compared with control-injected (black bar) icK0 animals $\left(p=2.207 \times 10^{-11}\right.$, Student's $t$ test). $\boldsymbol{D}$, Numbers of regenerated SCG10 + axons at defined distances from the crush site are significantly lower in tamoxifen-injected icK0 animals (gray bars) compared with control animals (black bars; $p=0.003$ at $1.5 \mathrm{~mm} ; 0.003$ at $2 \mathrm{~mm} ; 0.01$ at $2.5 \mathrm{~mm} ; 0.01$ at $3 \mathrm{~mm} ; 0.02$ at $3.5 \mathrm{~mm}$; 0.002 at $4 \mathrm{~mm} ; 0.03$ at $4.5 \mathrm{~mm} ; 0.01$ at $5 \mathrm{~mm}$ from the crush site; Student's $t$ test for each point). $E, F$, IHC of longitudinal sections of crushed sciatic nerves stained with $S C G 10$ at 3 dpi revealed that SCG10(+) axons extend farther in wild-type (WT; $\boldsymbol{E})$ compared with cKO mutants (F; white arrows). Crush sites are marked with white vertical lines. Scale bar: (in $\boldsymbol{B}) \boldsymbol{E}, \boldsymbol{F}, 500 \mu \mathrm{m} . \boldsymbol{G}, \boldsymbol{H}$, Quantifications reveal that axon regeneration is significantly impaired in cKO Gpr126 mutants compared with WT littermates. $\mathbf{G}$, Lengths of longest axons are shorter in cKO (gray bar) animals compared with WT (black bar) animals ( $p=0.002$, Student's $t$ test). $\boldsymbol{H}$, Numbers of regenerated SCG10+ axons at 3 dpi is significantly lower in cK0 mice (gray bars) compared with WT controls (black bars; $p=0.02$ at $1.5 \mathrm{~mm} ; 0.01$ at $2 \mathrm{~mm} ; 0.006$ at $2.5 \mathrm{~mm} ; 0.002$ at $3 \mathrm{~mm} ; 0.0005$ at $3.5 \mathrm{~mm} ; 0.0004$ at $4 \mathrm{~mm} ; 0.01$ at $4.5 \mathrm{~mm} ; 0.01$ at $5 \mathrm{~mm}$ from the crush site. Student's $\mathrm{t}$ test for each point). Error bars are shown as \pm SD.

between wild-type and Gpr126 mutant SCs following injury. Of the 84 genes tested, four chemokines were significantly downregulated in cKO nerves: $\mathrm{Ccl} 2, \mathrm{Ccl3}, \mathrm{Cxcl10}$, and Tnf (Fig. 9G). Importantly, Ccl2 (Toews et al., 1998; Taskinen and Röyttä, 2000) and $\operatorname{Tnf}$ (Chernov et al., 2015) are both normally upregulated after peripheral nerve injury. Additionally, Tnf is important for the immunological activation of SCs (Qin et al., 2008; Mao et al., 2010), and Ccl2 is required for macrophage recruitment after peripheral nerve injury (Toews et al., 1998). Interestingly, of the four significant hits, Tnf is the most downregulated in Gpr126 mutant nerves, and previous studies have shown that Tnf is required for inducing the expression of $\mathrm{Ccl} 2$ (Chen et al., 2004; Lin et al., 2007; Ho et al., 2008; Xia et al., 2011), Ccl3 (Wang et al., 2012), and Cxcl10 (Hardaker et al., 2004; Qi et al., 2009) in other contexts. To ensure that chemokine gene expression is not altered in cKO SCs without injury, we repeated the chemokine array analysis to compare uninjured cKO sciatic nerves with wild-type controls at 8 weeks of age. Of the 84 tested genes, only MapK1 was slightly (1.5-fold) upregulated in uninjured cKO nerves compared with controls (data not shown, $N=3, p=0.04$, Student's $t$ test). Additionally, we observed no difference in macrophage number in cKO sciatic nerves compared with wild-type sibling control nerves at 8 weeks of age (data not shown). Together, these data suggest that Gpr126 is required for inducing expression of Tnf to activate the expression of chemokines by repair SCs to recruit peripheral macrophages after nerve injury.

\section{Gpr126 is required in SCs for proper axon regeneration} following injury

Following myelin and axonal debris clearance in the distal portion of an injured nerve, regenerating axons grow through tracts called Büngner bands, which contain SCs and their original basal laminae (Chen et al., 2007; Jessen et al., 2015). Given that Gpr126 has two known basal lamina binding partners-collagen IV
(Paavola et al., 2014) and laminin-211 (Petersen et al., 2015)_and that aGPCRs have adhesive functions as well as signaling functions (Langenhan et al., 2013), we reasoned that Büngner bands, and subsequently axon regeneration, might be impaired following loss of Gpr126 in SCs. To test this, we performed IHC on longitudinal sections at 3 dpi with an anti-superior cervical ganglion 10 (SCG10) antibody to selectively label regenerating axons (Cho et al., 2013; Shin et al., 2014). SCG10 levels rapidly decline in distal axons following injury, accumulate in proximal axons within $1 \mathrm{~h}$ following injury, and are maintained during axon regeneration (Shin et al., 2014). We observed that axon regeneration is significantly impaired in tamoxifen-injected icKO mice compared with control-injected mice (Fig. 11A-D) by measuring the lengths of the longest SCG10(+) axons (Fig. 11C; $N=3, p=2.2 \times 10^{-13}$, Student's $t$ test) as well as SCG10 $(+)$ axon numbers at standard intervals from the crush site (Fig. 11D; $N=3, p$ values given in figure legend). This analysis suggested that Gpr126 in SCs is required for axon regeneration. However, myelin debris clearance is impaired in icKO mice (Fig. 4E), which could potentially affect axon regeneration. To control for this, we next injured sciatic nerves of cKO mice. As cKO SCs never form myelin (Mogha et al., 2013), no myelin debris can be present following injury. Similar to icKO mice, we observed significantly impaired axon regeneration by anti-SCG10 staining 3 dpi in cKO mice compared with littermate Gpr126 $6^{f l f l} ; D h^{C r e}{ }^{C r}$ controls (Fig. $11 E-H ; N=3$ for $\mathrm{cKO}, N=4$ for controls, $p=0.002$ for length of the longest axon, Student's $t$ test; $p$ values for axon numbers at standard distances from the crush site given in figure legend).

Next, we wanted to determine whether the observed axon regeneration defects were transient; however, SCG-10 staining is only effective for regenerating axons up to $\sim 3 \mathrm{dpi}$ (Shin et al., 2014). Therefore, we instead examined NMJ innervation of the EDL muscle, which is innervated by the sciatic nerve, at $12 \mathrm{dpi}$. We stained NMJ end plates with BTX and counterstained axons 

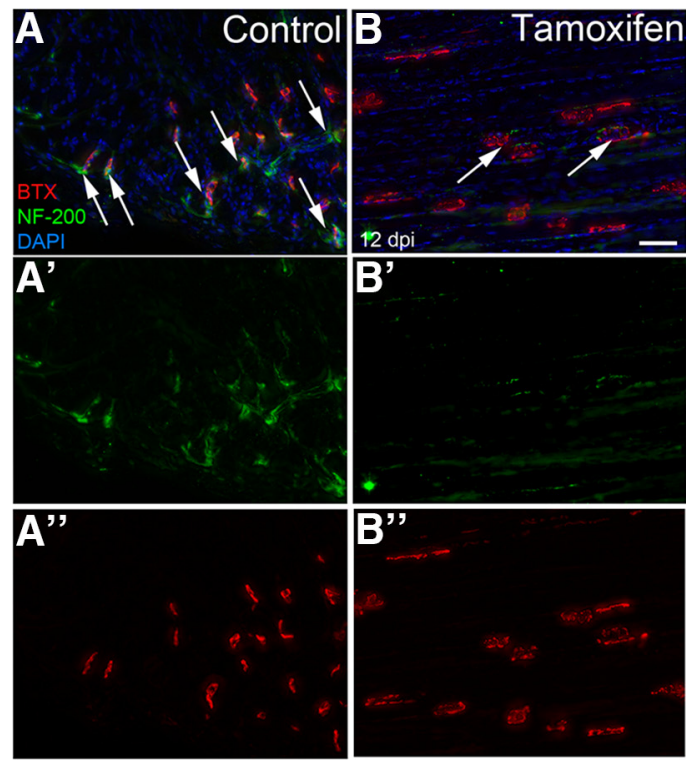

\section{C}

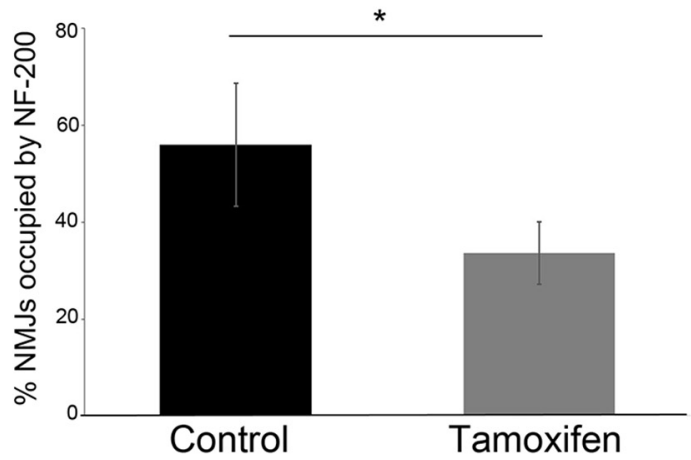

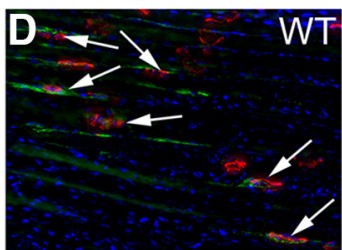
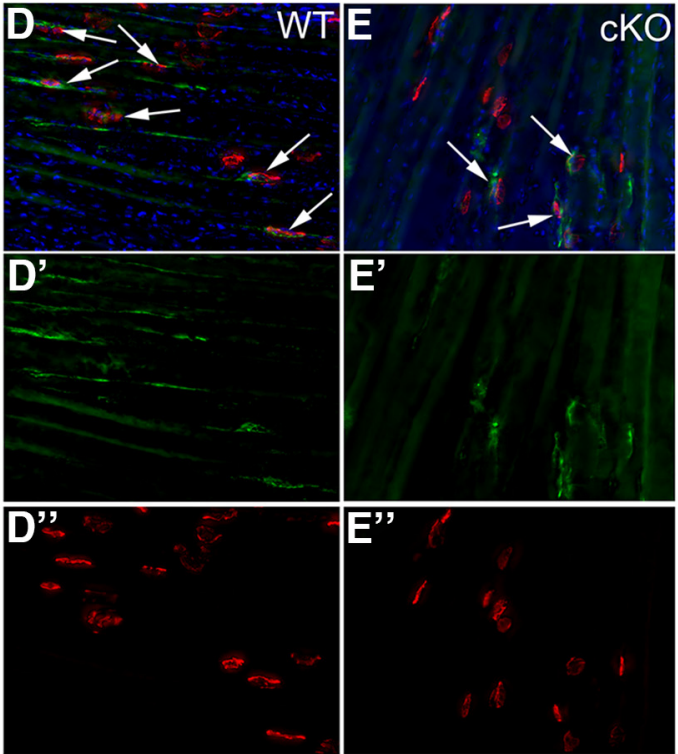

F

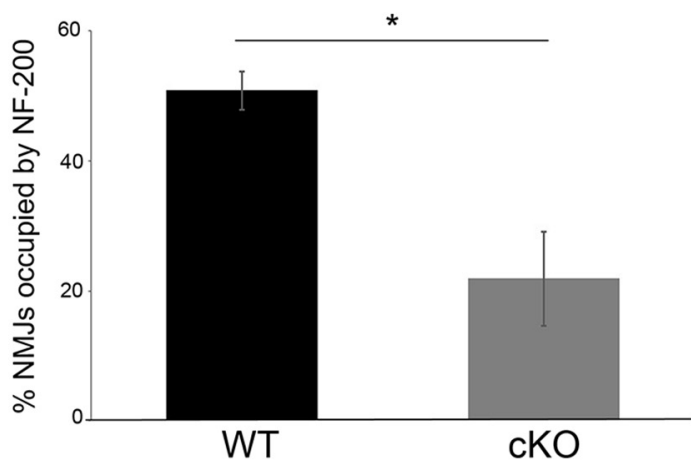

Figure 12. NMJ reinnervation is impaired when Gpr126 is absent in SCS. A-C, NMJ staining with Alexa-555-conjugated BTX (red) and NF-200 (green) reveals that significantly fewer NMJs are reinnervated at $12 \mathrm{dpi}$ (white arrows) in tamoxifen-injected animals $\left(\boldsymbol{B}-\boldsymbol{B}^{\prime \prime}\right)$ compared with control-injected animals $\left(\boldsymbol{A}-\boldsymbol{A}^{\prime \prime} ; N=3, p=0.05\right.$, Student's $t$ test). $\boldsymbol{D}-\boldsymbol{F}$, Significantly fewer NMJs are reinnervated at $12 \mathrm{dpi}$ in $\mathrm{KKO}$ mice $\left(\boldsymbol{F}-\boldsymbol{F}^{\prime \prime}\right)$ compared with wild-type (WT) siblings ( $\boldsymbol{D}-\boldsymbol{D}^{\prime \prime} ; N=3, p=0.003$, Student's test). Scale bar: (in $\left.\boldsymbol{B}\right) \boldsymbol{A}-\boldsymbol{B}^{\prime \prime}, \boldsymbol{D}-\boldsymbol{E}^{\prime \prime}, 50 \mu \mathrm{m}$. Error bars are shown as $\pm \mathbf{S D}$.

with NF-200 (Cho et al., 2013, 2015). This analysis revealed that even at $12 \mathrm{dpi}$, the number of NMJs occupied by NF-200(+) axons was significantly lower in tamoxifen-injected animals compared with control-injected animals (Fig. 12A-C; $N=3, p=0.05$, Student's $t$ test), although contralateral uninjured NMJ innervation was unaffected (data not shown). We observed a similar phenotype in cKO EDL muscle compared with wild-type siblings (Fig. 12D-F; $N=3, p=0.003$, Student's $t$ test), again with contralateral NMJs unaffected (data not shown). Together, these results suggest that Gpr126 is nonautonomously required in SCs for peripheral axon regeneration following nerve injury.

\section{Discussion}

In regeneration as in development, the peripheral nerve is a complex organ that requires interactions and communication between many cell types for proper function. SCs "sense" axon injury by an unknown mechanism, and as Wallerian degeneration and subsequent axon regeneration proceed, SCs respond with remarkable plasticity. Mature phenotypes are lost and the cells are transformed into dedicated repair SCs that play many roles in nerve repair and functional recovery. Repair SCs clear debris and recruit macrophages to the distal stump. Repair SC morphology drastically flattens and elongates (Arthur-Farraj et al., 2012), but the basal lamina that once encompassed the mature SC persists. Repair SCs form longitudinal columns within the basal lamina tubes, and these units are collectively referred to as Büngner bands. Regenerating axons grow through Büngner bands and require extracellular matrix cues and trophic support from repair SCs for their migration and survival (Chen et al., 2007; Brosius Lutz and Barres, 2014). Finally, SCs further demonstrate their capacity for dramatic change by once more acquiring mature phenotypes, and in the case of myelinating SCs, by remyelinating the regenerated axons.

Although the signals that regulate remyelination are not completely understood, many developmental pathways are reinitiated (Chen et al., 2007). The aGPCR Gpr126 is essential for developmental myelination (Monk et al., 2009, 2011; Mogha et al., 2013) and, intriguingly, Gpr126 mRNA and protein are maintained in mature SCs (Mogha et al., 2013; Fig. 1). Although prolonged loss of Gpr126 in SCs is associated with abnormal axon-glial interactions after $\sim 1$ year (Küffer et al., 2016), our data suggest that Gpr126 is dispensable for myelin maintenance up to 4 months after deletion (Figs. 2, 3). The lack of a myelin maintenance phenotype up to 4 months following loss of Gpr126 permitted us to perform nerve-injury studies without confounding homeostatic impairments. We noted a significant reduction in the number of remyelinated axons and persistence of myelin debris at 21 dpi (Fig. 4B,D-F), and our marker and TEM analyses suggested that Gpr126(+) SCs were capable of proper remy- 
elination while Gpr126(-) SCs were not (Figs. 5, 6). In addition to this $\mathrm{SC}$-autonomous function in remyelination, we also observed interesting non-SC-autonomous phenotypes in icKO and cKO mutants following injury; namely, reduced macrophage recruitment and impaired axon regeneration (Figs. 9-12).

Following nerve injury, repair SCs upregulate several chemokines, including interleukins, TNF- $\alpha$, leukemia inhibitory factor, and MCP-1, which serve to recruit macrophages to the distal nerve (Martini et al., 2008; Brosius Lutz and Barres, 2014). These macrophages phagocytose myelin and axonal debris, and are key for facilitating eventual nerve repair (Brück, 1997; Martini et al., 2008; Chen et al., 2015). Interestingly, here we show that Gpr126 is required in SCs to upregulate chemokine expression following nerve injury, particularly $\mathrm{Tnf}$ and some of its downstream targets-Ccl2, Ccl3, and Cxcl10 (Fig. 10G). Dissecting the molecular relationships between Gpr126 and these chemokines in macrophage recruitment will be an important next step as will determining how reduced macrophage numbers directly affect repair in this model. Despite their importance, however, macrophages are not completely essential for debris clearance in the distal stump, as repair SCs are also highly proficient at this task. Indeed, for the first $5 \mathrm{~d}$ following injury (Liu et al., 1995; Perry et al., 1995), SCs are primarily responsible for debris clearance and, in mouse mutants that lack macrophage recruitment to distal nerve due to loss of the chemokine receptor $\mathrm{Ccr} 2$, SCs are capable of clearing myelin debris alone (Niemi et al., 2013). It was recently shown that repair SCs clear myelin debris by a specialized form of autophagy termed "myelinophagy" (Gomez-Sanchez et al., 2015). Therefore, our observation that myelin debris persists up to 21 dpi (Fig. $4 E$ ) suggests that Gpr 126 is also required in SCs for efficient myelinophagy, and future work is required to directly test this hypothesis.

We also observed impaired axon regeneration and NMJ reinnervation in SC-specific Gpr126 mutants that was not the consequence of increased myelin debris, as both icKO (myelin debris present) and cKO mutants (myelin debris absent) displayed the same phenotype (Figs. 11, 12). Given that the extracellular matrix proteins laminin-211 and collagen IV are binding partners for Gpr126 (Paavola et al., 2014; Petersen et al., 2015), it is possible that the Büngner band basal lamina tubes are disrupted without Gpr126 in such a way that axon regeneration is inhibited. Although we did not observe obvious loss of the basal lamina by TEM, abnormal basal lamina loops and outfoldings were evident in Gpr126 icKO mutants up to 21 dpi (Fig. 4D), suggesting that the stability of this structure was in some way compromised. We note that laminin proteins are known modulators of axon regeneration following nerve injury. Antibody-mediated perturbation of the $\alpha 2$-laminin chain reduces axon regeneration on nerve sections, while genetic loss of the $\gamma 1$-laminin chain impairs axon regeneration in vivo (Agius and Cochard, 1998; Chen and Strickland, 2003). Thus, perhaps Gpr126 and laminin-211 interactions are required in regeneration in addition to development. Interestingly, loss of $c$-Jun in SCs also impairs axon regeneration in addition to neuronal survival (Arthur-Farraj et al., 2012). c-Jun is a transcription factor that functions as a key mediator of repair SC transformation following injury, although c-Jun levels are upregulated in Gpr126 mutant SCs after nerve crush (Fig. 8). In the future, it will be important to investigate whether c-Junindependent/Gpr126-dependent pathways in SCs are required for nerve repair.

In SC development, a major pathway downstream of Gpr126 activation is the elevation of cAMP to initiate terminal differentiation (Monk et al., 2009, 2011; Mogha et al., 2013). Whereas a driving role for cAMP in SC differentiation has been known for decades (Mokuno et al., 1988; Monuki et al., 1989; Mirsky et al., 1990; Morgan et al., 1991; Scherer et al., 1994), the function of this second messenger in the injury response is less clear, as previous studies draw different conclusions regarding levels of cAMP in distal nerve stumps following injury. cAMP levels were reported to be increased 1-6 h after nerve-crush injury in rabbit (Appenzeller and Palmer, 1972) and decreased 2-35 d after cut or crush injury in rats (Podulso et al., 1995). There are also conflicting reports regarding the effect of exogenous cAMP elevation on nerve repair (McQuarrie et al., 1977; Gershenbaum and Roisen, 1980 ), and cAMP certainly functions in peripheral axons in addition to SCs (Kilmer and Carlsen, 1984, 1987). Given that Gpr126 can couple to Gi-family proteins in addition to Gs (Mogha et al., 2013; Liebscher et al., 2014) and that Gpr126 has G-protein signaling-independent functions in SCs (Petersen et al., 2015), we cannot conclude that a lack of cAMP elevation underlies any of the phenotypes we observe in the SC-specific Gpr126 mutants following injury. Indeed, it is perhaps counterintuitive that such a strong differentiation signal would be required in SCs while they are maintaining a repair, nondifferentiated phenotype, although we predict that cAMP elevation is required for remyelination following re-establishment of axon-SC interactions in repair as in development. As the sensitivity and in vivo applications for cAMP sensors improve (Langenhan et al., 2015), it will be very interesting to monitor cAMP levels in individual SCs following nerve injury and during repair responses and remyelination.

In neurobiology, aGPCRs have traditionally been studied in the context of development (Langenhan et al., 2016), but here we demonstrate key functions for Gpr126 in nerve regeneration in the adult animal. We show that Gpr126 is required in SCs for axon remyelination, mirroring its essential developmental role. We also show that SC-derived Gpr126 is needed for proper macrophage recruitment, myelin debris clearance, and axon regeneration, uncovering new and unexpected roles for this aGPCR in peripheral nerve repair. As a GPCR, Gpr 126 represents an attractive therapeutic target in PNS disease and injury, and given the link between Gpr126 and laminin 211, this work has important clinical implications for MDC1A patients.

\section{References}

Agius E, Cochard P (1998) Comparison of neurite outgrowth induced by intact and injured sciatic nerves: a confocal and functional analysis. J Neurosci 18:328-338. Medline

Akassoglou K, Yu WM, Akpinar P, Strickland S (2002) Fibrin inhibits peripheral nerve remyelination by regulating Schwann cell differentiation. Neuron 33:861-875. CrossRef Medline

Aoyama N, Molin DGM, Mentink MMT, Koerten HK, De Ruiter MC, Gittenberger-De Groot AC, Poelmann RE (2004) Changing intracellular compartmentalization of beta-galactosidase in the ROSA26 reporter mouse during embryonic development: a light- and electron-microscopic study. Anat Rec A Discov Mol Cell Evol Biol 279A:740-748. CrossRef Medline

Appenzeller O, Palmer G (1972) The cyclic AMP (adenosine 3',5' phosphate) content of sciatic nerve: changes after nerve crush. Brain Res 42:521-524. CrossRef Medline

Arthur-Farraj PJ, Latouche M, Wilton DK, Quintes S, Chabrol E, Banerjee A, Woodhoo A, Jenkins B, Rahman M, Turmaine M, Wicher GK, Mitter R, Greensmith L, Behrens A, Raivich G, Mirsky R, Jessen KR (2012) c-Jun reprograms Schwann cells of injured nerves to generate a repair cell essential for regeneration. Neuron 75:633-647. CrossRef Medline

Bauder AR, Ferguson TA (2012) Reproducible mouse sciatic nerve crush and subsequent assessment of regeneration by whole mount muscle analysis. J Vis Exp pii:3606. CrossRef Medline

Brosius Lutz AB, Barres BA (2014) Contrasting the glial response to axon injury in the central and peripheral nervous systems. Dev Cell 28:7-17. CrossRef Medline 
Brück W (1997) The role of macrophages in Wallerian degeneration. Brain Pathol 7:741-752. CrossRef Medline

Chen P, Piao X, Bonaldo P (2015) Role of macrophages in Wallerian degeneration and axonal regeneration after peripheral nerve injury. Acta Neuropathol 130:605-618. CrossRef Medline

Chen YM, Chiang WC, Lin SL, Wu KD, Tsai TJ, Hsieh BS (2004) Dual regulation of tumor necrosis factor-alpha-induced CCL2/monocyte chemoattractant protein-1 expression in vascular smooth muscle cells by nuclear factor-kappaB and activator protein-1: modulation by type III phosphodiesterase inhibition. J Pharmacol Exp Ther 309:978-986. CrossRef Medline

Chen ZL, Strickland S (2003) Laminin gammal is critical for Schwann cell differentiation, axon myelination, and regeneration in the peripheral nerve. J Cell Biol 163:889-899. CrossRef Medline

Chen ZL, Yu WM, Strickland S (2007) Peripheral regeneration. Annu Rev Neurosci 30:209-233. CrossRef Medline

Chernov AV, Dolkas J, Hoang K, Angert M, Srikrishna G, Vogl T, Baranovskaya S, Strongin AY, Shubayev VI (2015) The calcium-binding proteins S100A8 and S100A9 initiate the early inflammatory program in injured peripheral nerves. J Biol Chem 290:11771-11784. CrossRef Medline

Cho Y, Sloutsky R, Naegle KM, Cavalli V (2013) Injury-induced HDAC5 nuclear export is essential for axon regeneration. Cell 155:894-908. CrossRef Medline

Cho Y, Shin JE, Ewan EE, Oh YM, Pita-Thomas W, Cavalli V (2015) Activating injury-responsive genes with hypoxia enhances axon regeneration through neuronal HIF-1 $\alpha$. Neuron 88:720-734. CrossRef Medline

Demberg LM, Rothemund S, Schöneberg T, Liebscher I (2015) Identification of the tethered peptide agonist of the adhesion $\mathrm{G}$ protein-coupled receptor GPR64/ADGRG2. Biochem Biophys Res Commun 464:743747. CrossRef Medline

Finzsch M, Schreiner S, Kichko T, Reeh P, Tamm ER, Bösl MR, Meijer D, Wegner M (2010) Sox10 is required for Schwann cell identity and progression beyond the immature Schwann cell stage. J Cell Biol 189:701712. CrossRef Medline

Gershenbaum MR, Roisen FJ (1980) The effects of dibutryl cyclic adenosine monophosphate on the degeneration and regeneration of crush-lesioned rat sciatic nerves. Neuroscience 5:1565-1580. CrossRef Medline

Giera S, Deng Y, Luo R, Ackerman SD, Mogha A, Monk KR, Ying Y, Jeong SJ, Makinodan M, Bialas AR, Chang BS, Stevens B, Corfas G, Piao X (2015) The adhesion G protein-coupled receptor GPR56 is a cell autonomous regulator of oligodendrocyte development. Nat Commun 6:6121. CrossRef Medline

Glenn TD, Talbot WS (2013) Analysis of Gpr126 function defines distinct mechanisms controlling the initiation and maturation of myelin. Development 140:3167-3175. CrossRef Medline

Gomez-Sanchez JA, Carty L, Iruarrizaga-Lejarreta M, Palomo-Irigoyen M, Varela-Rey M, Griffith M, Hantke J, Macias-Camara N, Azkargorta M, Aurrekoetxea I, De Juan VG, Jefferies HB, Aspichueta P, Elortza F, Aransay AM, Martínez-Chantar ML, Baas F, Mato JM, Mirsky R, Woodhoo A et al. (2015) Schwann cell autophagy, myelinophagy, initiates myelin clearance from injured nerves. J Cell Biol 210:153-168. CrossRef Medline

Hardaker EL, Bacon AM, Carlson K, Roshak AK, Foley JJ, Schmidt DB, Buckley PT, Comegys M, Panettieri RA Jr, Sarau HM, Belmonte KE (2004) Regulation of TNF-alpha- and IFN-gamma-induced CXCL10 expression: participation of the airway smooth muscle in the pulmonary inflammatory response in chronic obstructive pulmonary disease. FASEB J 18:191193. Medline

Ho AW, Wong CK, Lam CW (2008) Tumor necrosis factor-alpha upregulates the expression of CCL2 and adhesion molecules of human proximal tubular epithelial cells through MAPK signaling pathways. Immunobiology 213:533-544. CrossRef Medline

Jaegle M, Ghazvini M, Mandemakers W, Piirsoo M, Driegen S, Levavasseur F, Raghoenath S, Grosveld F, Meijer D (2003) The POU proteins Brn-2 and Oct-6 share important functions in Schwann cell development. Genes Dev 17:1380-1391. CrossRef Medline

Jessen KR, Mirsky R (2008) Negative regulation of myelination: relevance for development, injury, and demyelinating disease. Glia 56:1552-1565. CrossRef Medline

Jessen KR, Mirsky R, Lloyd AC (2015) Schwann cells: development and role in nerve repair. In: Glia (Barres BA, Freeman MR, Stevens B, eds), pp 205-220. New York: Cold Spring Harbor Laboratory.

Kilmer SL, Carlsen RC (1984) Forskolin activation of adenylate cycles in vivo stimulates nerve regeneration. Nature 307:455-457. CrossRef Medline

Kilmer SL, Carlsen RC (1987) Chronic infusion of agents that increase cyclic AMP concentration enhances the regeneration of mammalian peripheral nerves in vivo. Exp Neurol 95:357-367. CrossRef Medline

Küffer A, Lakkaraju AK, Mogha A, Petersen SC, Airich K, Doucerain C, Marpakwar R, Bakirci P, Senatore A, Monnard A, Schiavi C, Nuvolone M, Grosshans B, Hornemann S, Bassilana F, Monk KR, Aguzzi A (2016) The prion protein is an agonistic ligand of the $\mathrm{G}$ protein-coupled receptor Adgrg6. Nature 536:464-468. CrossRef Medline

Langenhan T, Aust G, Hamann J (2013) Sticky signaling-adhesion class G protein-coupled receptors take the stage. Sci Signal 6:re3. CrossRef Medline

Langenhan T, Barr MM, Bruchas MR, Ewer J, Griffith LC, Maiellaro I, Taghert PH, White BH, Monk KR (2015) Model organisms in G protein-coupled receptor research. Mol Pharmacol 88:596-603. CrossRef Medline

Langenhan T, Piao X, Monk KR (2016) Adhesion G protein-coupled receptors in nervous system development and disease. Nat Rev Neurosci 17: 550-561. CrossRef Medline

Leone DP, Genoud S, Atanasoski S, Grausenburger R, Berger P, Metzger D, Macklin WB, Chambon P, Suter U (2003) Tamoxifen-inducible gliaspecific Cre mice for somatic mutagenesis in oligodendrocytes and Schwann cells. Mol Cell Neurosci 22:430-440. CrossRef Medline

Liebscher I, Schön J, Petersen SC, Fischer L, Auerbach N, Demberg LM, Mogha A, Cöster M, Simon KU, Rothemund S, Monk KR, Schöneberg T (2014) A tethered agonist within the ectodomain activates the adhesion G protein-coupled receptors GPR126 and GPR133. Cell Rep 9:20182026. CrossRef Medline

Lin SK, Kok SH, Shun CT, Hong CY, Wang CC, Hsu MC, Liu CM (2007) Tumor necrosis factor-alpha stimulates the expression of C-C chemokine ligand 2 gene in fibroblasts from the human nasal polyp through the pathways of mitogen-activated protein kinase. Am J Rhinol 21:251-255. CrossRef Medline

Liu HM, Yang LH, Yang YJ (1995) Schwann cell properties: 3. C-fos expression, bFGF production, phagocytosis and proliferation during Wallerian degeneration. J Neuropathol Exp Neurol 54:487-496. CrossRef Medline

Livak KJ, Schmittgen TD (2001) Analysis of relative gene expression data using real-time quantitative PCR and the $2^{-\Delta \Delta} C_{\mathrm{T}}$ method. Methods 25: 402-408. CrossRef Medline

Mao XJ, Zhang XM, Zhang HL, Quezada HC, Mix E, Yang X, Winblad B, Adem A, Zhu J (2010) TNF-alpha receptor 1 deficiency reduces antigenpresenting capacity of Schwann cells and ameliorates experimental autoimmune neuritis in mice. Neurosci Lett 470:19-23. CrossRef Medline

Martini R, Fischer S, López-Vales R, David S (2008) Interactions between Schwann cells and macrophages in injury and inherited demyelinating disease. Glia 56:1566-1577. CrossRef Medline

McQuarrie IG, Grafstein B, Gershon MD (1977) Axonal regeneration in the rat sciatic nerve: effect of a conditioning lesion and of dbcAMP. Brain Res 132:443-453. CrossRef Medline

Mercuri E, Pennock J, Goodwin F, Sewry C, Cowan F, Dubowitz L, Dubowitz V, Muntoni F (1996) Sequential study of central and peripheral nervous system involvement in an infant with merosin-deficient congenital muscular dystrophy. Neuromuscul Disord 6:425-429. CrossRef Medline

Mirsky R, Dubois C, Morgan L, Jessen KR (1990) 04 and A007-sulfatide antibodies bind to embryonic Schwann cells prior to the appearance of galactocerebroside; regulation of the antigen by axon-Schwann cell signals and cyclic AMP. Development 109:105-116. Medline

Mogha A, Benesh AE, Patra C, Engel FB, Schöneberg T, Liebscher I, Monk KR (2013) Gpr126 functions in Schwann cells to control differentiation and myelination via G-protein activation. J Neurosci 33:17976-17985. CrossRef Medline

Mokuno K, Sobue G, Reddy UR, Wurzer J, Kreider B, Hotta H, Baron P, Ross AH, Pleasure D (1988) Regulation of Schwann cell nerve growth factor receptor by cyclic adenosine $3^{\prime}, 5^{\prime}$-monophosphate. J Neurosci Res 21: 465-472. Medline

Monk KR, Naylor SG, Glenn TD, Mercurio S, Perlin JR, Dominguez C, Moens CB, Talbot WS (2009) A G protein-coupled receptor is essential for Schwann cells to initiate myelination. Science 325:1402-1405. CrossRef Medline

Monk KR, Oshima K, Jörs S, Heller S, Talbot WS (2011) Gpr126 is essential 
for peripheral nerve development and myelination in mammals. Development 138:2673-2680. CrossRef Medline

Monuki ES, Weinmaster G, Kuhn R, Lemke G (1989) SCIP: a glial POU domain gene regulated by cAMP. Neuron 3:783-793. CrossRef Medline

Morgan L, Jessen KR, Mirsky R (1991) The effects of cAMP on differentiation of cultured Schwann cells: progression from an early phenotype $(04+)$ to a myelin phenotype (P0+, GFAP-, N-CAM-, NGFreceptor-) depends on growth inhibition. J Cell Biol 112:457-467. CrossRef Medline

Niemi JP, DeFrancesco-Lisowitz A, Roldán-Hernández L, Lindborg JA, Mandell D, Zigmond RE (2013) A critical role for macrophages near axotomized neuronal cell bodies in stimulating nerve regeneration. J Neurosci 33:16236-16248. CrossRef Medline

Paavola KJ, Sidik H, Zuchero JB, Eckart M, Talbot WS (2014) Type IV collagen is an activating ligand for the adhesion $\mathrm{G}$ protein-coupled receptor GPR126. Sci Signal 7:ra76. CrossRef Medline

Perry VH, Tsao JW, Fearn S, Brown MC (1995) Radiation-induced reductions in macrophage recruitment have only slight effects on myelin degeneration in sectioned peripheral nerves of mice. Eur J Neurosci 7:271-280. CrossRef Medline

Petersen SC, Luo R, Liebscher I, Giera S, Jeong SJ, Mogha A, Ghidinelli M, Feltri ML, Schöneberg T, Piao X, Monk KR (2015) The adhesion GPCR GPR126 has distinct, domain-dependent functions in Schwann cell development mediated by interaction with laminin-211. Neuron 85:755769. CrossRef Medline

Poduslo JF, Walikonis RS, Domec MC, Berg CT, Holtz-Heppelmann CJ (1995) The second messenger, cyclic AMP, is not sufficient for myelin gene induction in the peripheral nervous system. J Neurochem 65:149159. Medline

Qi XF, Kim DH, Yoon YS, Jin D, Huang XZ, Li JH, Deung YK, Lee KJ (2009) Essential involvement of cross-talk between IFN-gamma and TNF-alpha in CXCL10 production in human THP-1 monocytes. J Cell Physiol 220: 690-697. CrossRef Medline

Qin Y, Cheng C, Wang H, Shao X, Gao Y, Shen A (2008) TNF-alpha as an autocrine mediator and its role in the activation of Schwann cells. Neurochem Res 33:1077-1084. CrossRef Medline

Quijano-Roy S, Renault F, Romero N, Guicheney P, Fardeau M, Estournet B (2004) EMG and nerve conduction studies in children with congenital muscular dystrophy. Muscle Nerve 29:292-299. CrossRef Medline
Scherer SS, Wang DY, Kuhn R, Lemke G, Wrabetz L, Kamholz J (1994) Axons regulate Schwann cell expression of the POU transcription factor SCIP. J Neurosci 14:1930-1942. Medline

Shin JE, Cho Y, Beirowski B, Milbrandt J, Cavalli V, DiAntonio A (2012) Dual leucine zipper kinase is required for retrograde injury signaling and axonal regeneration. Neuron 74:1015-1022. CrossRef Medline

Shin JE, Geisler S, DiAntonio A (2014) Dynamic regulation of SCG10 in regenerating axons after injury. Exp Neurol 252:1-11. CrossRef Medline

Shorer Z, Philpot J, Muntoni F, Sewry C, Dubowitz V (1995) Demyelinating peripheral neuropathy in merosin-deficient congenital muscular dystrophy. J Child Neurol 10:472-475. CrossRef Medline

Soriano P (1999) Generalized lacZ expression with the ROSA26 Cre reporter strain. Nat Genet 21:70-71. CrossRef Medline

Stoveken HM, Hajduczok AG, Xu L, Tall GG (2015) Adhesion G proteincoupled receptors are activated by exposure of a cryptic tethered agonist. Proc Natl Acad Sci U S A 112:6194-6199. CrossRef Medline

Taskinen HS, Röyttä M (2000) Increased expression of chemokines (MCP-1, MIP-1alpha, RANTES) after peripheral nerve transection. J Peripher Nerv Syst 5:75-81. CrossRef Medline

Toews AD, Barrett C, Morell P (1998) Monocyte chemoattractant protein 1 is responsible for macrophage recruitment following injury to sciatic nerve. J Neurosci Res 53:260-267. CrossRef Medline

Wang M, Tang D, Shu B, Wang B, Jin H, Hao S, Dresser KA, Shen J, Im HJ, Sampson ER, Rubery PT, Zuscik MJ, Schwarz EM, O'Keefe RJ, Wang Y, Chen D (2012) Conditional activation of beta-catenin signaling in mice leads to severe defects in intervertebral disc tissue. Arthritis Rheum 64: 2611-2623. CrossRef Medline

Xia L, Lu J, Xiao W (2011) Blockage of TNF-alpha by infliximab reduces CCL2 and CCR2 levels in patients with rheumatoid arthritis. J Investig Med 59:961-963. CrossRef Medline

Zhu Q, Song L, Peng G, Sun N, Chen J, Zhang T, Sheng N, Tang W, Qian C, Qiao Y, Tang K, Han JD, Li J, Jing N (2014) The transcription factor Pou3f1 promotes neural fate commitment via activation of neural lineage genes and inhibition of external signaling pathways. Elife 3. CrossRef Medline

Zorick TS, Syroid DE, Arroyo E, Scherer SS, Lemke G (1996) The transcription factors SCIP and Krox-20 mark distinct stages and cell fates in Schwann cell differentiation. Mol Cell Neurosci 8:129-145. CrossRef Medline 